Research Article

\title{
Silica Coating of Metal-Loaded H-ZSM-22 to Form the Core-Shell Nanostructures: Characterization, Textural Properties, and Catalytic Potency in the Esterification of Oleic Acid
}

\author{
Maryam Haghighi (iD) and Mehranoosh Fereidooni \\ Department of Chemistry, Faculty of Physics \& Chemistry, Alzahra University, P.O. Box 1993891176, Tehran, Iran \\ Correspondence should be addressed to Maryam Haghighi; m.haghighi@alzahra.ac.ir
}

Received 24 May 2021; Revised 13 October 2021; Accepted 22 November 2021; Published 24 December 2021

Academic Editor: Prem Kumar Seelam

Copyright (c) 2021 Maryam Haghighi and Mehranoosh Fereidooni. This is an open access article distributed under the Creative Commons Attribution License, which permits unrestricted use, distribution, and reproduction in any medium, provided the original work is properly cited.

\begin{abstract}
In this study, ZSM-22 was synthesized using N,N-diethylaniline as a template through a hydrothermal method. The proton and various metals such as zirconium, strontium, and iron were immobilized on the surface of obtained zeolites through the ion exchange method. The catalysts were studied by Fourier-Transform Infrared Spectroscopy (FT-IR), X-Ray Diffraction (XRD), Brunauer-Emmett-Teller (BET) adsorption isotherms, Transmission Electron Microscope (TEM), Scanning Electron Microscope (SEM), Inductively Coupled Plasma-Optical Emission Spectrometry (ICP-OES) elemental analysis, and Temperature-Programmed Desorption of ammonia (TPD- $\mathrm{NH}_{3}$ ) technique for determining the number of acid sites. In the esterification reaction of oleic acid, the operating conditions such as catalyst dosage, temperature, molar ratio of methanol to oil, and reaction time were optimized and adjusted at $11 \mathrm{wt} \%, 70^{\circ} \mathrm{C}, 10: 1$, and $48 \mathrm{~h}$ subsequently. The maximum yield\% of $48.07 \%$ was achieved in the presence of Zr-H-ZSM-22 at optimum conditions. In order to improve the efficiency of three zeolites Zr-H-ZSM-22, Fe-H-ZSM22, and Sr-H-ZSM-22, the core-shell structures with $\mathrm{SiO}_{2}$ coating were prepared. Zr-H-ZSM-22@SiO 2 was less active than $\mathrm{Zr}-\mathrm{H}-$ ZSM-22 due to the $\mathrm{SiO}_{2}$ coverage of Lewis active sites.
\end{abstract}

\section{Introduction}

With the growing trend of fossil fuel consumption, the supply of petrodiesel has currently become a critical issue. Meanwhile, petroleum fuel consumption in internal combustion engines has been strictly controlled by environmental legislation due to its harmful effluents [1-5]. Due to the challenges resulting from global warming and the depletion of fuel sources along with the energy price fluctuations, developing a renewable energy source has become one of the world's highest priorities [6,7]. In this endeavor, biofuel has received ever-growing attention as an appropriate alternative for overcoming the problems associated with petroleum fuels $[8,9]$. Biofuels include gaseous and liquid fuels that are usually produced from renewable resources [10-13]. As the best alternative to fossil fuels, biodiesel shows considerable advantages, including good storing capability, low emission of toxic gas and organic compounds, biodegradability, and high calorific value in comparison with petroleum diesel [14, 15]. Different strategies have long been considered for biodiesel production from different biofeedstocks, such as agronomic crops, animal fats, or algae oils due to their remarkable lipid content [16-19]. Long-chain fatty acids (FAs) react with simple alcohols such as methanol or ethanol to obtain different monoalkyl esters by the esterification process $[20,21]$. Figure 1 shows that, as the main component of oil, triglyceride is converted into fatty acid alkyl ester and glycerol as a byproduct [22].

Typically, oil fraction with C16-C18 fatty acids can be used to produce biodiesel with moderate boiling points and desirable properties. Furthermore, oil refinement should be carried out to remove any undesirable components [23-25]. One of the serious concerns about unrefined oils is peroxide 


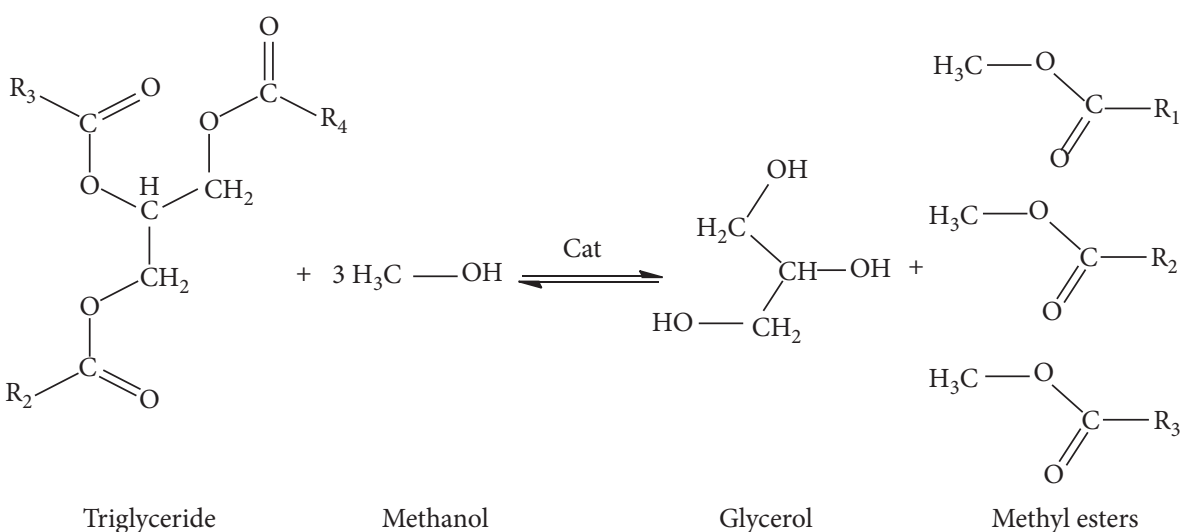

FIGURE 1: Biodiesel production via a typical transesterification reaction.

formation due to the reaction of unsaturated fatty acids with oxygen. Oxygen-containing functional groups are refined through hydrodeoxygenation to meet green fuel specifications identical with petrodiesel. Some supported metal catalysts, such as $\mathrm{NiMoS} / \mathrm{Al}_{2} \mathrm{O}_{3}$ and $\mathrm{Pt} / \mathrm{C}$, can improve the deoxygenation activity. Esterification can be catalyzed by alkaline catalysts with strong Brønsted base sites, which have some advantages over acid catalysts [26-28]. It should be noted that the undesirable saponification reaction between free fatty acids (FFAs) and water in basic environments is inevitable. For this purpose, the oil source should be purified by a pretreatment process in order to minimize the FFA content or water removal [29,30].

Since this purification process is quite expensive, acids can be considered a potential alternative in biodiesel production in two ways: transesterification and esterification. Nonetheless, the issue of corrosion in compression motors should first be resolved as the main disadvantage of acid catalysts [31, 32]. The remained soluble catalyst should be removed from the produced diesel by a washing process. Therefore, the purification of the product that increases processing costs is the main drawback of homogeneous catalysts [33].

Accordingly, heterogeneous inorganic acids such as metal-organic frameworks (MOFs), metal oxides, and zeolites have been used for biodiesel synthesis, as they can convert both FAs and FFAs without the corrosion side effect. Solid acid catalysts can be regenerated several times to reduce biodiesel cost production [31, 34-36]. In addition to transesterification, the esterification process is also an important reaction in biodiesel production. The development of good catalysts for this reaction is thus of interest for a broad range of applications [37, 38]. Zeolites are three-dimensional aluminosilicate structures composed of regular building blocks $[39,40]$. More recently, highly porous zeolites have come to play a key role in many chemical processes as a suitable catalyst, such as biodiesel production. These large commercial applications originate in the zeolite active sites (with Brønsted acidity) within regular channels and molecular cages [41]. The structure of channels and cavities are the most important features of zeolites. The active sites on the surface and in the cavities catalyze reactions, owing to the easy access of fatty acids to acidic sites, probably making molecules get trapped inside the pores and therefore intensifying catalyst selectivity, even though the diffusion of large molecules into the pores is limited [42-44]. Furthermore, diffusion limitation in the opposite direction (from the pores to the reaction environment) increases the contact time between the reactants and the inner acidic sites since it impedes molecular escape. Nonetheless, pore blockage may take place, and as a result, the development of zeolites with lower pore length or interconnected channels has been taken into consideration as well. Consequently, zeolite can serve as a molecular sieve owing to the dimensions and configuration of the channels $[45,46]$. Among the different types of zeolites, ZSM-22 has received more attention due to its high $\mathrm{Si} / \mathrm{Al}$ ratio and medium pore size. In general, this selective zeolite is desirable due to its porosity, cavity volume, high specific surface area, high acidity, and favorable catalytic properties $[47,48]$. The catalytic activity of zeolite is affected by pore size and structure. The $\mathrm{Si} / \mathrm{Al}$ ratio is an important parameter for the successful synthesis of mesopores, as it affects zeolite acidity [49]. ZSM-22 zeolite, which has a TON morphology, has been extensively used in catalytic esterification to produce biodiesel. TON-type zeolites such as Theta-1 and ZSM22 have one-dimensional structures with channels running parallel to the c-axis. The channels are formed from elliptical 10 -membered (10-MR) ring systems with an effective pore size of $0.46 \mathrm{~nm} \times 0.57 \mathrm{~nm}$. TON-type zeolites are synthesized using polyamines such as diethylenetriamine and triethylenetetramine as Structure-Directing Agents (SDAs). ZSM22 facilitates biodiesel production due to its internal acid sites [50].

The purpose of this study is to synthesize biodiesel using oleic acid and methanol by means of catalytic esterification. ZSM-22-based catalysts were used in this research. With the help of ion exchange techniques $[38,51,52]$, several different metals, such as $\mathrm{Fe}, \mathrm{Zr}$, and $\mathrm{Sr}$, were placed on catalytic sites and examined under different synthesis conditions. Synthesis and optimization of the synthesis method and modifying the zeolite structure of zeolite are the key objectives of this research. Binding some metals to the surface, changing the ratio of silica to aluminum, and controlling the 
synthesis time, $\mathrm{pH}$, and calcination time are the main tasks performed to optimize the synthesis and modify the zeolite structure. In continuation, the silica coating of metal-loaded zeolites is prepared to obtain progressive composite materials with a core-shell structure. Various studies have examined the effect of silica coverage on zeolite selectivity for a range of catalytic reactions, such as isomerization and cracking. Typically, the external acid sites of the core are surrounded by the shell and may not play a catalytic role in the esterification process. These studies have reported that the inactive shell (silica) tends to make the external acid sites passive through the coating.

\section{Experimental}

2.1. Chemicals. $\mathrm{KOH}(99 \%), \mathrm{Al}_{2}\left(\mathrm{SO}_{4}\right)_{3} \cdot 18 \mathrm{H}_{2} \mathrm{O}$ (99\%), tetraethyl orthosilicate (TEOS) (99\%) as a silica source, N,Ndiethylaniline (99\%) as a structure-directing agent, $\mathrm{Fe}\left(\mathrm{NO}_{3}\right)_{2} \cdot 4 \mathrm{H}_{2} \mathrm{O}, \mathrm{Sr}\left(\mathrm{NO}_{3}\right)_{2}, \mathrm{ZrCl}_{4}$, pure oleic acid (99\%), and $\mathrm{HNO}_{3}(83 \%)$ were purchased from Merck Co. These compounds were used for zeolite synthesis and biodiesel production. Absolute methanol ( $\geq 99 \%)$ was prepared from Ghatran Shimi Co. All reagents for zeolite synthesis and esterification reaction were used as received without further purification. Double distilled water was applied for all synthesis and purification.

2.2. Instruments. The produced zeolites were characterized by various analysis instruments, including FT-IR (Bruker Tensor 27), XRD (Philips X-ray diffractometer ( $\mathrm{Cu} \mathrm{K} \alpha 1$ radiation, cobalt anode, wavelength of $1.78890 \AA, 40 \mathrm{kV}$, $40 \mathrm{~mA}$ ), BET (Belsorp-mini 1l, BEL, Japan), TEM (ZeissEM10C-100 kV), SEM (VEGA3 LMU), ICP-OES (VARIAN

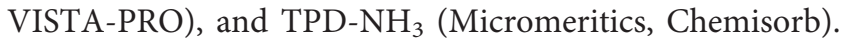
Biodiesel samples were studied by gas chromatography (GC) (Agilent, 6890 series. GC system). Energy Dispersive X-ray Spectroscopy (EDS, Model EM 3200, KykY) is used for elemental analysis of the prepared zeolites. The produced methyl esters were detected by gas chromatography-mass spectrometry (GC-MS) analyzer (model: Agilent $6890 \mathrm{~N}$ Network GC system-5973N Mass selective detector).

2.3. Synthesis of Catalysts Based on ZSM-22. The synthesis of hierarchical ZSM-22 zeolite was performed through a hydrothermal treating of silica and aluminum sources. As an extension of the foregoing researches, N,N-diethylaniline was employed as an organic structure-directing agent (OSDA) template. In this research, the postsynthesis modifications were implemented to increase the acidic properties and catalytic performance of zeolite. In order to study the effect of the structure of ZSM-22 in promoting the esterification process, the conventional ZSM-22 was compared with its corresponding core-shell structure. In the first stage, the aluminum sulfate source (Solution A) was prepared by mixing the $0.175 \mathrm{~g}$ of aluminum sulfate octadecahydrate, $1 \mathrm{~mL}$ of $\mathrm{N}, \mathrm{N}$-diethylaniline, and an alkaline solution made up of $0.39 \mathrm{~g}$ of potassium hydroxide and $20 \mathrm{~mL}$ of distilled water. The formed solution was stirred continuously at $200 \mathrm{rpm}$. In continuation, the silica solution was obtained by dissolution of $3.5 \mathrm{~mL}$ of TEOS solution and $30 \mathrm{~mL}$ of distilled water (Solution B). A homogeneous white gel was formed by adding the silica gel to the aluminum sulfate solution. The mixture was kept stirring at $25^{\circ} \mathrm{C}$ for $1 \mathrm{~h}$. Afterward, the resulting homogeneous gel was transferred into a stainless-steel autoclave and subjected to the hydrothermal treatment at $160^{\circ} \mathrm{C}$ for $48 \mathrm{~h}$ (crystallization time). Finally, the solid product was recovered by filtration, washed several times to neutralize, and then dried at $100^{\circ} \mathrm{C}$ for $1 \mathrm{~h}$. The product was dried and calcined at $550^{\circ} \mathrm{C}$ for $6 \mathrm{~h}$ in air atmosphere.

As it will be expected, the $\mathrm{Si} / \mathrm{Al}$ ratio plays a key role in acidity, pore structure, textural properties, and catalytic strength of zeolite. An increase in Si/Al ratio can increase the average accessibility to acid Brønsted sites of the zeolite as the catalytically active site. A comprehensive study about the $\mathrm{Si} / \mathrm{Al}$ ratio enables the targeted designing of zeolite-based catalyst. Therefore, the zeolite was synthesized at different $\mathrm{Si}$ / $\mathrm{Al}$ molar ratio (the Si/Al molar ratios were fixed at 40, 50, 75, and 95). The gel preparation time and crystallization time can tune the pore structure and size toward a well-crystallized ZSM-22 zeolite. In this regard, the zeolite synthesis was performed through different crystallization times $(48 \mathrm{~h}$, $72 \mathrm{~h}$, and $96 \mathrm{~h}$ ) and calcination times ( $6 \mathrm{~h}$ and $12 \mathrm{~h}$ ) to adjust the optimum value.

The as-synthesized zeolites (ZSM-22) were converted to the $\mathrm{H}$ form via an ion exchange method by adding about $80 \mathrm{~mL}$ of $\mathrm{NH}_{4} \mathrm{NO}_{3}$ solution $(0.5 \mathrm{M})$ at $80^{\circ} \mathrm{C}$ for $3 \mathrm{~h}$ under reflux conditions. The prepared solid was dried at $100^{\circ} \mathrm{C}$ in an atmospheric oven and then calcined at $550^{\circ} \mathrm{C}$ for $6 \mathrm{~h}$. In continuation, different metals were exchanged in the structure of zeolite by the hydrothermal method and during synthesis. Thus, the samples were ion exchanged by impregnation with an aqueous solution of $\mathrm{Fe}\left(\mathrm{NO}_{3}\right)_{2} \cdot 4 \mathrm{H}_{2} \mathrm{O}$, $\mathrm{Sr}\left(\mathrm{NO}_{3}\right)_{2}$, and $\mathrm{ZrCl}_{4}$ through a hydrothermal method during zeolite synthesis to obtain the M-H-ZSM-22, where M denotes the metal. The ion exchange method for all cases is followed by a similar procedure. $0.2 \mathrm{~g}$ of metal salts was solubilized in $20 \mathrm{~mL}$ of distilled water along with the $0.39 \mathrm{~g}$ of potassium hydroxide, $0.175 \mathrm{~g}$ of aluminum sulfate octadecahydrate, and $1 \mathrm{~mL}$ of N,N-diethylaniline. In this process, the amount of TEOS (in solution B) was relatively duplicated to $6 \mathrm{~mL}$. In order to obtain a homogeneous solution, the mixing time of milky white gel was increased to $2 \mathrm{~h}$. The crystalline solids were filtered, washed several times with demineralized water, and dried for $1 \mathrm{~h}$ at $100^{\circ} \mathrm{C}$ in an oven. The organic template was removed by calcination at $550^{\circ} \mathrm{C}$ for $6 \mathrm{~h}$ to achieve the high porous medium. The calcined product was ion exchanged with $\mathrm{NH}_{4} \mathrm{NO}_{3}$ solution $(0.5 \mathrm{M})$ till the potassium content was removed from the zeolite. The protonic form was obtained by calcination treatment. The mass ratio of $\mathrm{Si} / \mathrm{Al}$ was fixed at 50 for all experiments (optimum ratio).

2.4. Synthesis of Core-Shell Structures. The core-shell structure was obtained by covering $\mathrm{SiO}_{2}$ on the core. In the proposed process, the core particles were prepared 
according to the procedure, which is the same as that of the metal-decorated zeolites, except the synthesis of zeolites which was carried out at $150^{\circ} \mathrm{C}$ for $60 \mathrm{~h}$. In the next step, zeolite suspension was dissolved in silicon dioxide, according to the following procedure. $2 \mathrm{~g}$ of core samples (including Sr-H-ZSM-22, Zr-H-ZSM-22, and Fe-H-ZSM22) was added to a homogeneous mixture of $7 \mathrm{~mL}$ of TEOS, $5 \mathrm{~mL}$ of ethanol, and $1.5 \mathrm{~mL}$ of $\mathrm{N}, \mathrm{N}$-diethylaniline. The resulting suspension was stirred for $1 \mathrm{~h}$ at lab temperature and neutralized with $\mathrm{HNO}_{3}$. Afterward, the coated cores were treated in an autoclave at $150^{\circ} \mathrm{C}$ for a prolonged time to $60 \mathrm{~h}$. The overgrowth particles were washed several times to adjust the solution at neutral $\mathrm{pH}$ and dried at $120^{\circ} \mathrm{C}$ for $1 \mathrm{~h}$. The calcination was retried at $550^{\circ} \mathrm{C}$ for a short time of $6 \mathrm{~h}$. The preparation method was performed for three different cores to obtain the following catalysts: Sr-H-ZSM-22@SiO Zr-H-ZSM-22@SiO 2 , and Fe-H-ZSM-22@SiO 2 .

2.5. Biodiesel Reaction. The esterification reaction of oleic acid was carried out in a $25 \mathrm{~mL}$ one-necked round bottom flask equipped with a cooling water reflux system. Initially, $3 \mathrm{~mL}$ of oleic acid was added to the reaction flask and heated up to the required temperature under vigorous stirring conditions. $4 \mathrm{~mL}$ amount of methanol and a certain amount of catalyst were added to the container. The flask was soaked in an oil bath to control the temperature throughout the reaction. After the temperature of the sample reached a suitable range of $65-85^{\circ} \mathrm{C}$, the esterification process proceeded under a defined reflux condition. Finally, heating was stopped, and the samples were centrifuged to separate the catalyst and different phases. The upper layer consists of methyl ester and excess solvent, while the glycerol settles into the lower layer. The upper phase was separated, and the excess methanol was evaporated by an evaporator fan. The collected product was analyzed by the gas chromatography method to calculate the yield of methyl oleate.

To enable a meaningful comparison of the efficiency of different catalysts, the produced catalysts were exposed under similar conditions in biodiesel production. The effect of different factors, including the reaction time $(4,8,16,24$, and $48 \mathrm{~h})$, the molar ratio of methanol to oil $(10: 1,20: 1$, and $30: 1)$, catalyst to oil wt\% (1-11 wt $\%)$, and the operating temperature $\left(65,70,80\right.$, and $\left.85^{\circ} \mathrm{C}\right)$, on yield\% of methyl oleate have been investigated.

\section{Results and Discussion}

3.1. Characterization of Catalysts. In this study, different samples were synthesized to achieve high potency catalysts for the esterification of oleic acid. The Si/Al ratio affects zeolite properties such as acidity, hydrophobicity, thermal stability, and ion exchange capacity of zeolites. Furthermore, $\mathrm{Si} / \mathrm{Al}$ ratio plays a key role in the catalytic performance of zeolite-based catalysts that can be measured by EDS analysis. In general, high ratios of Si/Al lead to the formation of amorphous structures. Even though lower ratios lead to the formation of more uniform structures and prevent particle agglomeration, reducing this ratio faces various challenges.
For instance, a very low ratio reduces the acidic nature, which causes the complete destruction of the zeolite structure in $\mathrm{pH}$ below 3 . Hence, it is very important to achieve the optimal ratio of $\mathrm{Si} / \mathrm{Al}$ in which the zeolite structure can be protected.

Frequent washing and calcination of the samples lead to the removal of $\mathrm{Si}$ amounts and a reduction in the ratio of $\mathrm{Si} /$ Al. These factors may cause a considerable difference between the initial and measured values. Therefore, in this investigation, the treated catalysts were analyzed by the EDS elemental analysis method. Si, Al, O, and $\mathrm{K}$ have been detected in the obtained zeolites in which the observed potassium is due to $\mathrm{KOH}$ used in the synthesis of zeolites. Initial values and measured amounts of the $\mathrm{Si} / \mathrm{Al}$ ratios are reported in Table 1. It can be observed that the $\mathrm{Si} / \mathrm{Al}$ ratios in the obtained H-ZSM-22 are about 21.7 and 29 (Entries 3 and 5 in Table 1), while the initial ratios are 50 and 95, respectively. Since most of the $\mathrm{Si}$ was removed during washing and thermal treating of the samples, the initial ratio of 50 was considered in the synthesis of the catalysts.

All FT-IR spectra were taken for the prepared wafer of samples at room temperature. Figures 2(a) and 2(b) show the FT-IR spectra of synthesized ZSM-22 and its protonated form, H-ZSM-22. An asymmetric band appeared at $3700-3745 \mathrm{~cm}^{-1}$ along with another band centered at $3600 \mathrm{~cm}^{-1}$ pertaining to the $\mathrm{OH}$ stretching region. These peaks correspond to bridging $\mathrm{Si}-\mathrm{OH}-\mathrm{Al}$ groups, which creates strong Brønsted acid sites. The addition of hydrogen ions to the structure of zeolite has caused low displacement at the peak location. The unchanged peak structure indicates the preservation of the catalyst structure after ion exchange. The stretching vibration adsorption band $\mathrm{C}-\mathrm{N}$ appears at $1282 \mathrm{~cm}^{-1}$. The adsorption band at $1335-1250 \mathrm{~cm}^{-1}$ is attributed to the presence of an aniline aromatic ring. Also, the adsorption band at $1619 \mathrm{~cm}^{-1}$ is related to the bending vibration of N-H. This absorbent band also appears as a stretching vibration in $3400-3350 \mathrm{~cm}^{-1}$ (double shoulder band, amines $I$ ).

Figures 2(c)-2(e) show the IR spectra for the three catalysts exchanged with $\mathrm{Fe}, \mathrm{Zr}$, and $\mathrm{Sr}$. The aluminum ion in the $\mathrm{Si}-\mathrm{OH}-\mathrm{Al}$ band was replaced by different transition metal ions to enhance the catalytic activity of the parent zeolite. The exchanged metals within zeolite shifted the hydroxyl groups (depending on the metal type) toward lower frequencies since the acidic properties of zeolites increased.

In this study, all three types of synthesized core-shell samples were characterized by IR spectra. As can be seen, the results of Fe-H-ZSM-22@SiO $\mathrm{O}_{2}, \mathrm{Zr}-\mathrm{H}-\mathrm{ZSM}-22 @ \mathrm{SiO}_{2}$, and Sr-H-ZSM-22@SiO 2 are depicted in Figure $2((\mathrm{f})-(\mathrm{h}))$.

The absorption band at $468 \mathrm{~cm}^{-1}$ is the bending vibration of the Si-O, which appears as a strong sharp peak. The absorption bands below $1500 \mathrm{~cm}^{-1}$ are assigned to the aluminosilicate structures in the zeolites. The observed peaks at $1000-1100 \mathrm{~cm}^{-1}$ for all the samples are attributed to the Si-O-Si adsorption band and could be due to the external asymmetric elongation. An external symmetric stretching vibration appeared in the range of $790-800 \mathrm{~cm}^{-1}$. The adsorption band at $3600 \mathrm{~cm}^{-1}$ is attributed to the 
TABLE 1: The synthesized catalysts in different conditions.

\begin{tabular}{|c|c|c|c|c|c|c|c|c|}
\hline Entry & Catalyst & $\begin{array}{r}\text { S } \\
\text { Targeted }\end{array}$ & $\begin{array}{l}\text { i/Al } \\
\text { Measured }^{\mathrm{a}}\end{array}$ & $\mathrm{pH}$ & $\begin{array}{l}\text { Synthesis temp. } \\
\left({ }^{\circ} \mathrm{C}\right)\end{array}$ & $\begin{array}{c}\text { Calcination temp. } \\
\left({ }^{\circ} \mathrm{C}\right)\end{array}$ & $\begin{array}{c}\text { Synthesis time } \\
\text { (h) }\end{array}$ & $\begin{array}{l}\text { Calcination time } \\
\text { (h) }\end{array}$ \\
\hline 1 & ZSM-22 & 50 & 23 & 8.1 & 160 & 550 & 48 & 6 \\
\hline 2 & H-ZSM-22 & 40 & 13.26 & 7.8 & 160 & 550 & 48 & 6 \\
\hline 3 & H-ZSM-22 & 50 & 21.7 & 7 & 160 & 550 & 48 & 12 \\
\hline 4 & H-ZSM-22 & 75 & 26.11 & 7.3 & 160 & 550 & 48 & 12 \\
\hline 5 & H-ZSM-22 & 95 & 29.54 & 7 & 160 & 550 & 48 & 12 \\
\hline 6 & H-ZSM-22 & 95 & 29 & 7.8 & 160 & 550 & 72 & 12 \\
\hline 7 & H-ZSM-22 & 95 & 28.8 & 7.7 & 160 & 550 & 96 & 12 \\
\hline 8 & Fe-H-ZSM-22 & $50^{\mathrm{b}}$ & $21.7^{\mathrm{c}}$ & 7.8 & 160 & 550 & 48 & 6 \\
\hline 9 & Sr-H-ZSM-22 & $50^{\mathrm{b}}$ & $21.7^{\mathrm{c}}$ & 7.4 & 160 & 550 & 48 & 6 \\
\hline 10 & Zr-H-ZSM-22 & $50^{\mathrm{b}}$ & $21.7^{\mathrm{c}}$ & 7.7 & 160 & 550 & 48 & 6 \\
\hline 11 & $\begin{array}{c}\mathrm{Fe}-\mathrm{H}-\mathrm{ZSM}-22 @ \\
\mathrm{SiO}_{2}\end{array}$ & $50^{\mathrm{b}}$ & $21.7^{\mathrm{c}}$ & 7.8 & 150 & 550 & 60 & 12 \\
\hline 12 & $\begin{array}{c}\text { Sr-H-ZSM-22@ } \\
\mathrm{SiO}_{2}\end{array}$ & $50^{\mathrm{b}}$ & $21.7^{\mathrm{c}}$ & 7.7 & 150 & 550 & 60 & 12 \\
\hline 13 & $\begin{array}{c}\mathrm{Zr}-\mathrm{H}-\mathrm{ZSM}-22 @ \\
\mathrm{SiO}_{2} \\
\end{array}$ & $50^{\mathrm{b}}$ & $21.7^{\mathrm{c}}$ & 7.3 & 150 & 550 & 60 & 12 \\
\hline
\end{tabular}

${ }^{\mathrm{a}} \mathrm{Si} / \mathrm{Al}$ ratio was measured by EDS analysis. ${ }^{\mathrm{b}}$ This value is the initially used ratio for H-ZSM-22 synthesis applied for metal immobilization and core synthesis. ${ }^{\mathrm{c}} \mathrm{The} \mathrm{Si} / \mathrm{Al}$ ratio was measured and reported for H-ZSM-22 used for metal immobilization and core synthesis.

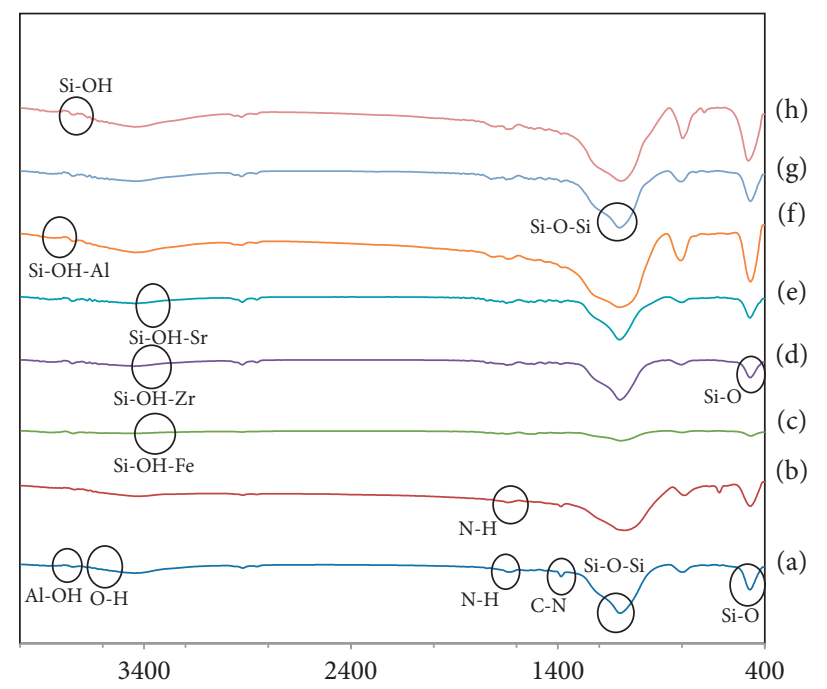

Figure 2: Infrared spectra of core-shell catalysts: (a) ZSM-22, (b) H-ZSM-22, (c) Fe-H-ZSM-22, (d) Zr-H-ZSM-22, (e) Sr-H-ZSM-22, (f) FeH-ZSM-22@SiO, , (g) Zr-H-ZSM-22@SiO 2 , and (h) Sr-H-ZSM-22@SiO 2 .

hydroxyl group that appeared as an active acidic site with strong vibration. As shown in Figure $2((\mathrm{f})-(\mathrm{h}))$, the adsorption bands at about $3610 \mathrm{~cm}^{-1}$ appeared for all zeolites assigned to $\mathrm{Si}-\mathrm{OH}-\mathrm{Al}$ and $\mathrm{Si}-\mathrm{OH}-\mathrm{M}$ groups. $\mathrm{M}$ denotes the exchanged metals, such as $\mathrm{Zr}, \mathrm{Sr}$, and $\mathrm{Fe}$, which are replaced by aluminum connections in the catalyst structure. The recorded adsorption band appearing at $3700 \mathrm{~cm}^{-1}$ represents hydrolyzed aluminum, which could be attributed to the acid Brønsted sites. A stretching vibration band of $\mathrm{Si}-\mathrm{OH}$ groups can be clearly observed at $3800 \mathrm{~cm}^{-1}$. This vibration appears due to the presence of free hydroxyl groups. The water-adsorbed band appears in the range of $1630-1650 \mathrm{~cm}^{-1}$. Notably, the wavenumbers of metaldecorated catalysts deviated from the measured peaks of H-ZSM-22 that was attributed to the effect of metal existence.
The metal amalgamation in the zeolite structure tends to improve catalytic activity and is accompanied by change in the structural characteristics. An element analysis was thus carried out using the ICP method for all three samples presented in Table 2. The results demonstrated that, in the studied sample, the concentration of strontium was four times higher than Fe and two times higher than Zr. As a result, in the porous structure of zeolite $\mathrm{H}-\mathrm{ZSM}-22$, the placement of strontium is higher than the other two metals in the pores. This property may be related to the poor ion binding between Fe and zeolite through adsorption in zeolite cavities. These results are consistent with the higher solubility of $\mathrm{Fe}\left(\mathrm{NO}_{3}\right)_{2} \cdot 4 \mathrm{H}_{2} \mathrm{O}$ and $\mathrm{ZrCl}_{4}$ relative to $\mathrm{Sr}\left(\mathrm{NO}_{3}\right)_{2}$. It seems that the solubility of $\mathrm{ZrCl}_{4}$ increases in the presence of $\mathrm{N}, \mathrm{N}$-diethylaniline. For this reason, high concentrations of $\mathrm{Fe}$ and $\mathrm{Zr}$ were dissolved in distilled water during the final 
TABLE 2: The element analysis of different catalysts using the ICPOES technique.

\begin{tabular}{lcc}
\hline Entry & Catalyst & The amount of metal ion $(\mathrm{ppm})$ \\
\hline 1 & Fe-H-ZSM-22 & 20042.8 \\
2 & Zr-H-ZSM-22 & 41441.8 \\
3 & Sr-H-ZSM-22 & 80648.5 \\
\hline
\end{tabular}

washing process. Based on this explanation, zeolite was found to show the highest adsorption capacity for $\mathrm{Sr}$ compared to the other metals. The $\mathrm{C}, \mathrm{O}, \mathrm{H}$, and $\mathrm{N}$ elements in the sample were not measured by ICP analysis.

The morphology and structure analysis of zeolites were studied using SEM images, as shown in Figure 3. The SEM micrographs of H-ZSM-22 (Figures 3(a) and 3(b)) show that highly porous nanoscale structures with a mean particle size of $60 \mathrm{~nm}$ were formed in this study. The SEM image of wellcrystallized H-ZSM-22 displays distinct rod-like particles with uniform shape and size. Moreover, the high pore density of zeolite results in a large surface area containing significant amounts of acidic site. The images of all the metal-decorated zeolites shown in Figures 3(c)-3(e) (Fe-HZSM-22, Zr-H-ZSM-22, and Sr-H-ZSM-22, resp.) demonstrate that rod-like particles were formed in all the cases without any significant change in the mean crystallite size. Although the SEM micrographs revealed that these complex media are formed by very small seeds, the aggregation phenomenon has occurred through metal loading. Moreover, the metal loading on the H-ZSM-22 caused an apparent modification in zeolite shape and a slight agglomeration irrespective of the element type. In this study, a series of core-shell samples with different silica concentrations were designed to perform the esterification. The morphologies of two types of silica-coated ZSM-22 were studied. The SEM images of Fe-H-ZSM-22@SiO ${ }_{2}$ and $\mathrm{Zr}-\mathrm{H}$ $\mathrm{ZSM}-22 @ \mathrm{SiO}_{2}$ catalysts can be seen in Figures 3(f) and 3(g), respectively. Crystal growth was formed by the core-shell structure with an apparent modification in the parent crystal structure. The samples consisted of the agglomerates of nanorods with some irregular shape particles due to the $\mathrm{SiO}_{2}$-coating posttreatment. Nonetheless, the images show relatively high aggregation in the samples, thereby decreasing the catalytic activity. This phenomenon occurs on the surface of the synthesized zeolites due to the $\mathrm{SiO}_{2}$ coverage on the sides of the open cells of zeolite as a shell. Therefore, the growth process in this method was strongly affected by the $\mathrm{SiO}_{2}$ aggregation in the mixture.

The SEM images of two core-shell samples (Figures 3(f) and $3(\mathrm{~g}))$ revealed that the particle diameter is in the range of $35-80 \mathrm{~nm}$, thinner than the parent crystals, which is due to the dissolution of the external surface of the crystals during the synthesis. Also, the hydrophobic silica shell inhibits crystal growth, which results in the formation of nanoscale crystals.

Using the Transmission Electron Microscope images, the core-shell nanostructure of Sr-H-ZSM-22@SiO ${ }_{2}$ was investigated. The TEM images of the crystalline structures showed that ZSM-22 was formed of regular and isolated pentagonal open cells surrounding the hexagonal cavities.
Rod-like individual crystals, pore descriptor, and pentasil unit cells can be observed in Figures 4(a) and 4(b). The SEM images of the core-shell zeolites showed that large and complex agglomerates formed during the $\mathrm{SiO}_{2}$ coverage process. Monodispersed isolated particles with moderate aggregation can be seen in TEM images. In other words, the nucleation and growth of the core-shell ZSM-22 structure improved by the isolated particles. The TEM images revealed that the growth of new particles occurs directly on the external surface of the zeolite particles. It can be observed from Figure 4(b) that a silicon dioxide shell has formed around the zeolitic core. The pores are large enough to construct a relatively high porous open-cell medium. Mesoporous ZSM-22-based catalysts were prepared by controlling the silicon addition to the zeolite suspension during the postprocessing stage.

The X-ray diffractogram in Figure 5(a) belongs to TONtype zeolites. As can be seen, the nanostructure corresponds to the TON structure of H-ZSM-22 with JCPDS card no. 37-0386 as the referable structure. According to XRD data, the chemical formula of $\mathrm{H}-\mathrm{ZSM}-22$ corresponds to $\mathrm{H}_{2} \mathrm{Si}_{20} \mathrm{O}_{41} \cdot \mathrm{xH}_{2} \mathrm{O}$. The indistinct lines in the diffractogram indicate the low crystallinity.

Regarding the XRD pattern, the amorphous phase can be observed accompanying the crystalline sample with a distinct change in intensity of diffraction peaks. This means that, due to the use of a high $\mathrm{Si} / \mathrm{Al}$ ratio, TON-type zeolite did not form completely, and an MFI type or amorphous phase was thus formed, as shown in Figure 5. This demonstrates that a low $\mathrm{Si} / \mathrm{Al}$ ratio has a stronger tendency than the high $\mathrm{Si} / \mathrm{Al}$ ratio to form crystalline zeolites.

Though the silicon coverage helps to form the amorphous phase, as can be seen in Figure 5 ((a)-(d)), a broad amorphous peak is present at a $2 \theta$ angle of $24.71^{\circ}$, which is ascribed to crystalline plane 101 . The crystal plane 101 is assigned to the formation of the ZSM-22 structure. For all the samples, the characteristic peak of ZSM-22 may be seen at $25^{\circ}$. The appeared peaks are assigned to pentasil-type zeolite with MFI topology. TON noninterconnecting framework is constructed of the periodic unit cells, which are connected into the layer. 10-membered ring (10-MR) elliptical channels have been diagnosed in this structure, composed of double 5-MR linked together by 6-MR [53]. Nonetheless, in some published papers, 5-MR was proposed as a unit cell [54-56]. As noted, the silica source and $\mathrm{pH}$ of the solution play a key role in the production of an appropriate precursor and the crystallization of the TON structure. It was found that using the TEOS silica source can intensify the amorphous nature. Evidence shows the Sr-HZSM-22 catalyst has more crystalline percent than other synthesized catalysts, and its XRD pattern corresponds to JCPDS card no. 2035-74.

The crystallographic data of H-ZSM-22 is represented in Table 3.

3.2. Textural Properties. $\mathrm{N}_{2}$ adsorption-desorption isotherms were measured for the H-ZSM-22 sample as the base of all the prepared catalysts, as shown in Figure 6(a). The 


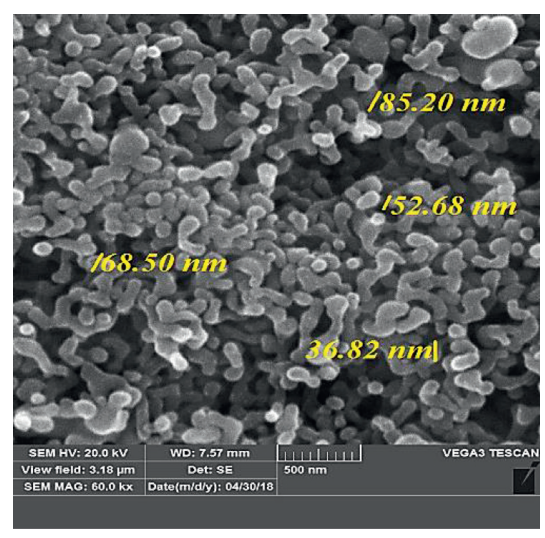

(a)

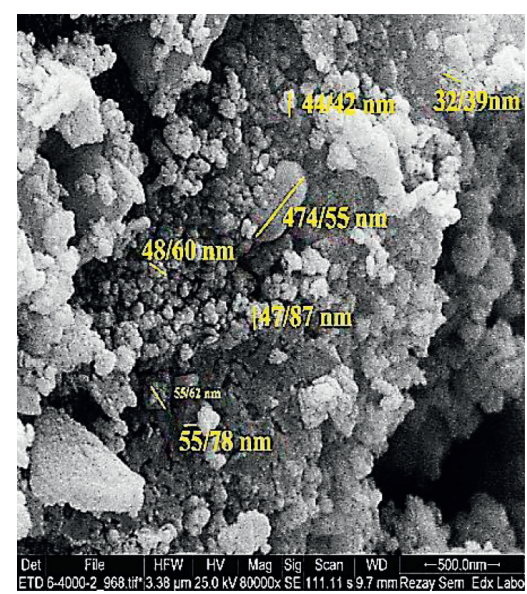

(d)

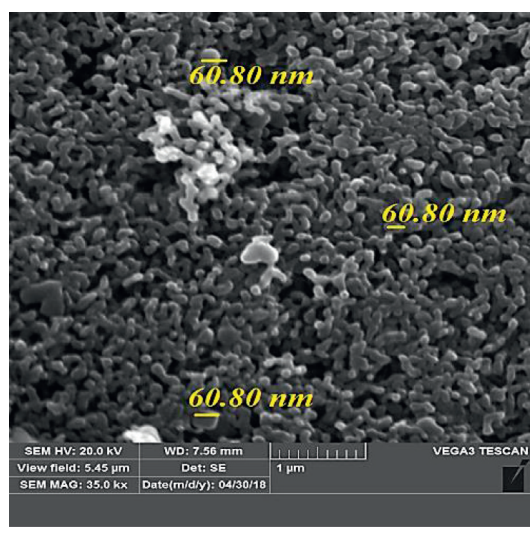

(b)

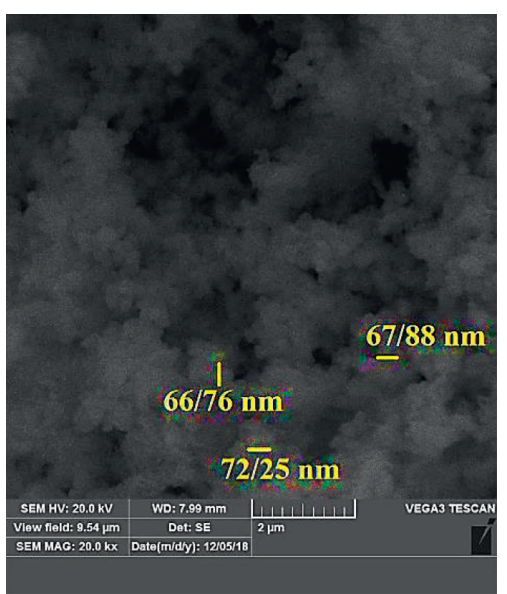

(e)

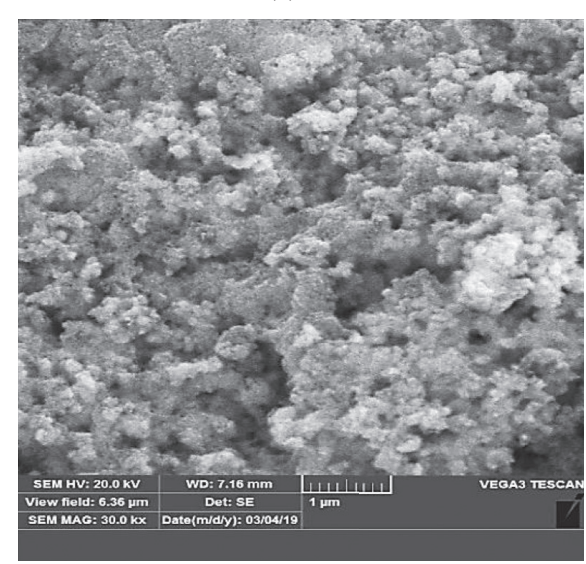

(g)

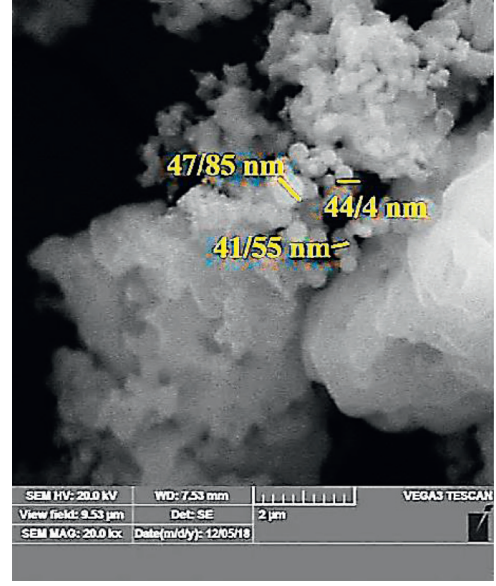

(c)

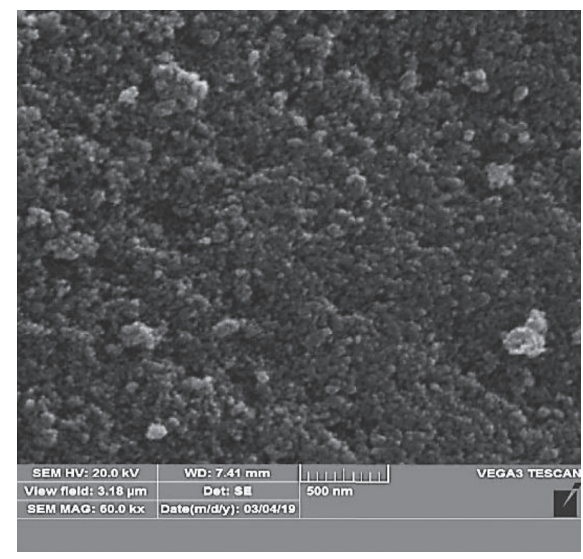

(f) 22 (e) Sr-H-ZSM-22, (f) Fe-H-ZSM-22@SiO ${ }_{2}$, and (g) Zr-H-ZSM-22@SiO 2 .

nitrogen adsorption-desorption isotherm at various pressures shows the IV-type isotherm for the H-ZSM-22 zeolite. It can be observed that, in the range of $\mathrm{P} / \mathrm{P} 0=0.1-0.8$, the adsorption remains almost constant, which is consistent with the previously reported results [39]. The BJH (Barrett, Joyner, and Halenda) pore size distribution for ZSM-22 and binder is presented in Figure 6(b). The sample exhibits the
type-IV of isotherms due to the presence of mesopores binder and type-I with micropore structure with an apparent H-4 hysteresis loop evidencing the existence of intercrystalline mesopores [57]. Figure 6(b) shows the BJH diagram based on the size of the cavities.

The average size of the cavities is in the range of $15-100 \mathrm{~nm}$, indicating the formation of mesoporous 


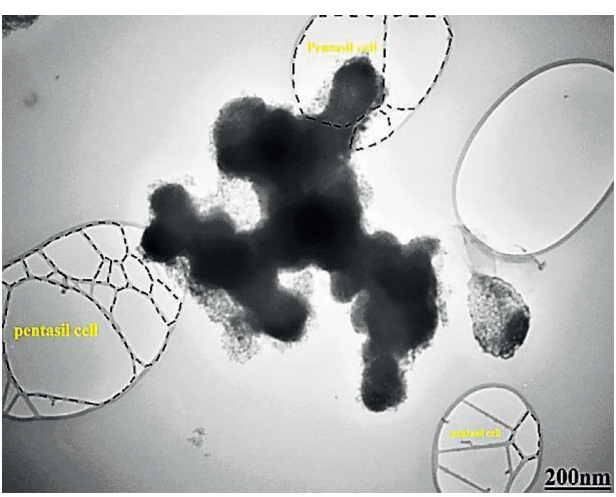

(a)

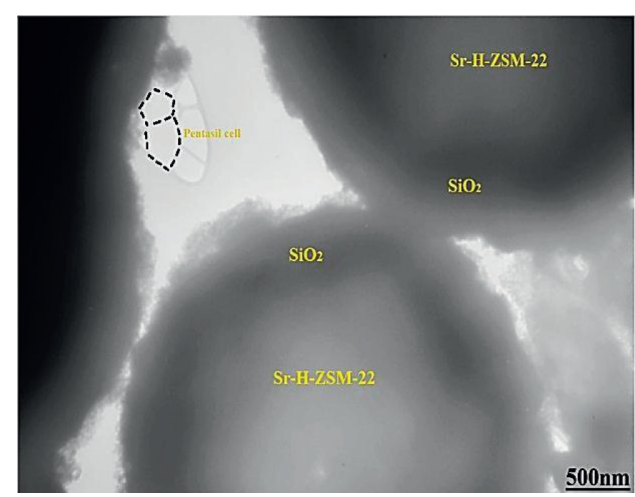

(b)

Figure 4: TEM images of nanoscale Sr-H-ZSM-22@SiO 2 : (a) detail of pores and (b) core-shell structure.

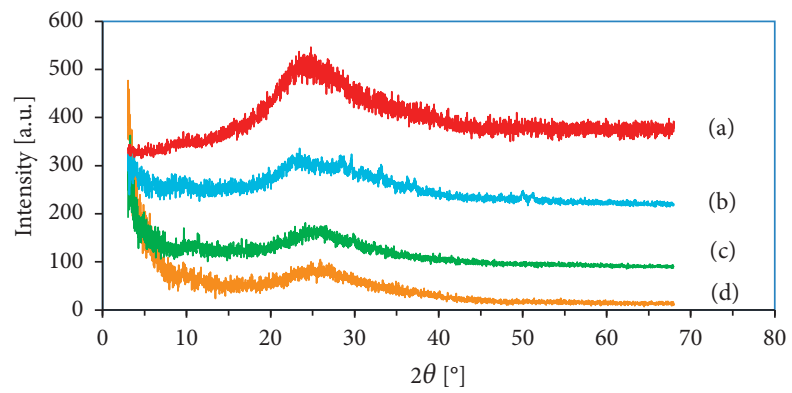

FIGURE 5: X-ray patterns of different samples exchanged with metals ions (cobalt anode, $\lambda \mathrm{k} \alpha=1.78 \AA$, kv 40, $40 \mathrm{~mA}$ ): (a) Fe-H-ZSM-22, (b) Zr-H-ZSM-22, (c) Sr-H-ZSM-22, and (d) H-ZSM-22.

TABLE 3: XRD data of H-ZSM-22.

\begin{tabular}{lccccc}
\hline $\begin{array}{l}\text { Crystal } \\
\text { system }\end{array}$ & $\begin{array}{c}\text { Space } \\
\text { group }\end{array}$ & $\begin{array}{c}\text { Space group } \\
\text { number }\end{array}$ & $\mathrm{a}(\AA)$ & $\mathrm{b}(\AA)$ & $\mathrm{c}(\AA)$ \\
\hline Tetragonal & $62 / \mathrm{Cmc}$ & 62 & 8.36 & 5.352 & 1.562 \\
\hline
\end{tabular}

structures in the zeolite [57]. ZSM-22 generally has a microporous structure, and with an increase in the ratio of $\mathrm{Si} /$ $\mathrm{Al}$, the average diameter of the cavities decreased to mesoscale. Since the catalytic performance of H-ZSM-22 with mesoporous cavities is higher than those of microporous structure, this modification can improve the catalytic activity of ZSM-22-based catalysts [57]. Figure 6(c) shows the BET adsorption and desorption graph for the H-ZSM-22 zeolite.

All the textural properties of the H-ZSM-22 sample were reported in Table 4.

The first challenge is to synthesize samples with a high surface area since $\mathrm{SiO}_{2}$ can block the pores, which is hard to avoid. The synthesis method should therefore be modified to prevent the pores from getting blocked by $\mathrm{SiO}_{2}$. For this purpose, a single-stage hydrothermal method was carried out that allowed for simultaneous zeolite synthesis and coreshell processing. The synthesized sample with a total $223.43 \mathrm{~m}^{2} \cdot \mathrm{g}^{-1}$ surface area, an external surface area of $169.76 \mathrm{~m}^{2} \cdot \mathrm{g}^{-1}$, and a pore volume of $0.0889 \mathrm{~cm}^{3} \cdot \mathrm{g}^{-1}$ is consistent with the data reported on the textural properties of industrial ZSM-22 [57, 58].
Nonetheless, after silicon coverage, the textural properties declined due to the diffusional constraints and relative pore blocking. The generation of up to $223.43 \mathrm{~m}^{2} \cdot \mathrm{g}^{-1}$ of the nanopore surface area leads to a micropore volume (down to $0.0889 \mathrm{~cm}^{3} \cdot \mathrm{g}^{-1}$ ) and $96 \%$ porosity, which are attributed to the formation of open-cell zeolite. A subsequent ion exchange treatment and metal redeposition, however, can block pore mouths and decrease the surface area. Most likely, due to the homogeneous metal distribution in the H-ZSM-22, only a small portion of the Brønsted sites is available. The metal particles immobilized in the parent zeolite bring new prospects to the catalytic performance of the zeolite. Nanoscale pore with $15.9 \mathrm{~nm}$ diameter determined the nanostructure of the zeolites.

3.3. Acidity of Zeolites. $\mathrm{NH}_{3}$-TPD analysis is used to evaluate the acidity of Zr-H-ZSM-22, which is assigned to the catalytic activity of the zeolite $[59,60]$. The $\mathrm{NH}_{3}$-TPD graph is shown in Figure 7 . The catalyst possesses two adsorption peaks centered at $180-200^{\circ} \mathrm{C}$ and $520^{\circ} \mathrm{C}$, which can be attributed to the adsorption of $\mathrm{NH}_{3}$ from relatively weak and strong acidic sites, respectively. The mercuric acid sites appeared at $200-350^{\circ} \mathrm{C}$. The first peak came from Lewis acid sites. The peak observed in the range of $600-800^{\circ} \mathrm{C}$ can be due to the failed transportation of the compound that is not the catalytic acid location. The sample with less strong acid sites was expected to show higher ester selectivity in the esterification reaction. 


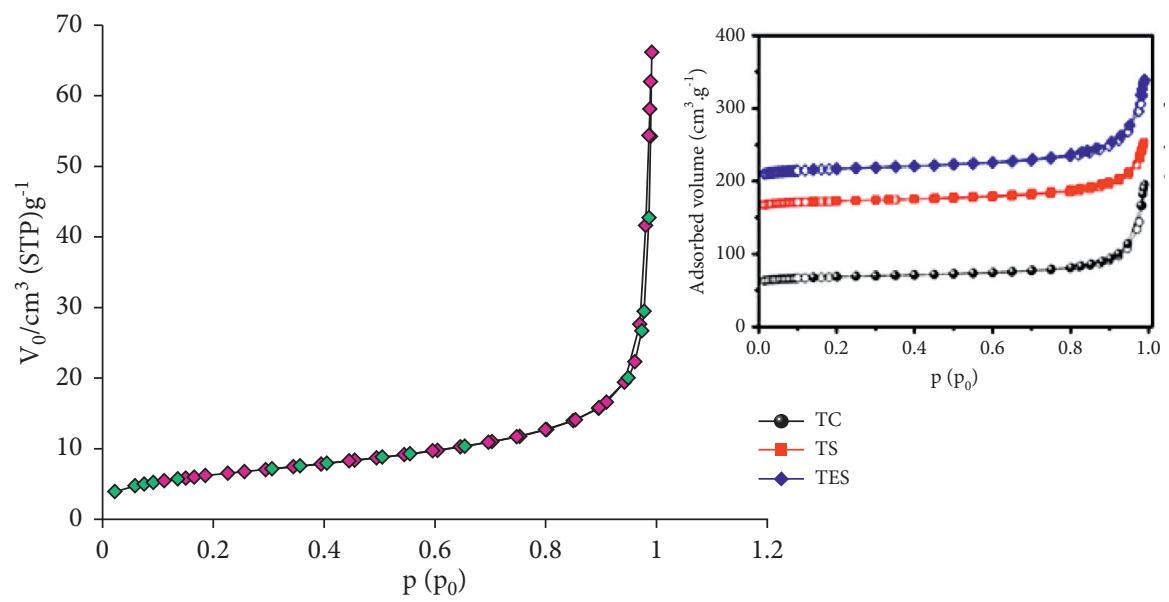

(a)

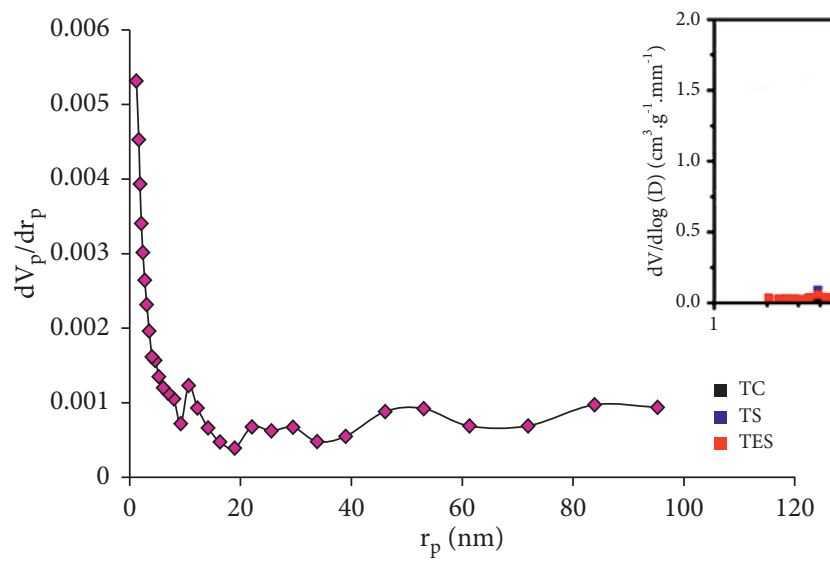

(b)

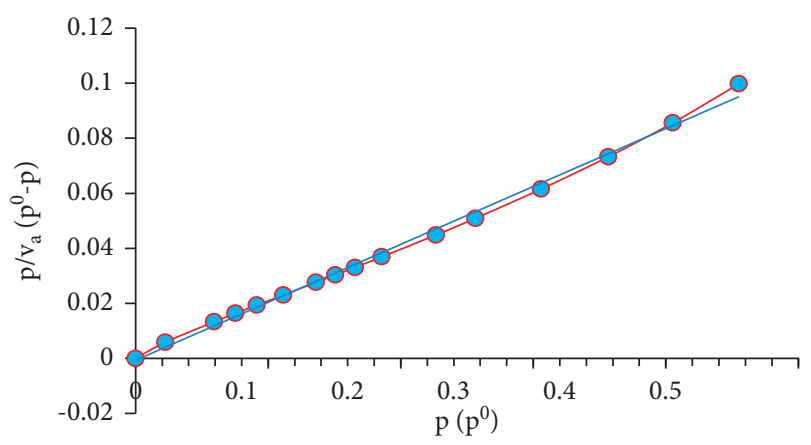

(c)

Figure 6: Textural properties of H-ZSM-22 zeolite: (a) $\mathrm{N}_{2}$ absorption-desorption isotherms at different pressures, comparison to reference [39], (b) dispersion diagram of zeolite cavities based on adsorption BJH, comparison to reference [39], and (c) BET adsorption and desorption graphs.

TABLE 4: The results of BET analysis of the H-ZSM-22 sample.

\begin{tabular}{lccccc}
\hline Catalyst & $\mathrm{S}_{\mathrm{BET}}\left(\mathrm{m}^{2} / \mathrm{g}\right)$ & $\mathrm{S}_{\mathrm{EXT}}\left(\mathrm{m}^{2} / \mathrm{g}\right)$ & $\mathrm{V}_{\text {micro }}\left(\mathrm{cm}^{3} / \mathrm{g}\right)$ & $\mathrm{dp}(\mathrm{nm})$ & Porosity $(\%)$ \\
\hline H-ZSM-22 & 223.43 & 169.76 & 0.088949 & 15.925 & 96.14 \\
\hline
\end{tabular}




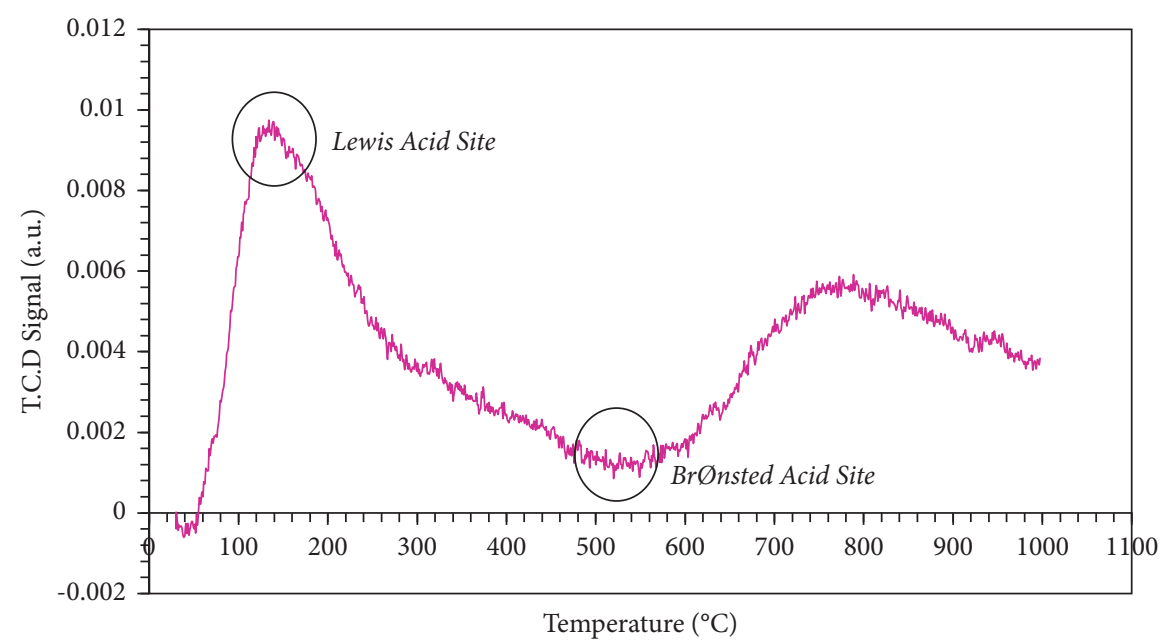

FIgURE 7: The TPD-NH 3 graph for Zr-H-ZSM-22 catalyst.

3.4. Investigation of Catalytic Activity. As already noted, oleic acid and methanol reacted in a reaction flask in the presence of a synthesized catalyst to produce methyl oleate. A gas chromatography apparatus was employed to analyze the results of the esterification reaction. Methyl oleate was detected by the GC-MS analysis as the product of the reaction (molecular weight=296). The methyl oleate was detected at a retention time of $11.605 \mathrm{~min}$, and its GC-MS chromatogram is shown in Figure 8.

The percent yield of the product was calculated according to the following formula:

$$
\text { Methyl Oleate }(\%)=\frac{C_{\text {methyl oleate }}}{C_{0}} \times 100,
$$

where $C_{0}$ and $C_{\text {methyl oleate }}$ are the initial concentration of oleic acid and the concentration of the produced methyl oleate, respectively. All amounts were measured according to the area of the peaks in the chromatogram. The first step of investigating the catalytic performance of different catalysts in the esterification of oleic acid involves determining the optimum operating conditions. To gain further insight into the catalytic activity of the prepared catalysts, multiple experiments have been performed under different operating conditions, such as different reaction times, temperatures, feed composition molar ratios, $\mathrm{pH}$ values, and weight percentages of the catalyst. To facilitate a meaningful comparison, the $\mathrm{Si} / \mathrm{Al}$ ratio should be fixed at a favorable value which was 50 in this study.

3.4.1. Effect of Temperature. In order to optimize the operating temperature, $3 \mathrm{~mL}$ of oleic acid and $4 \mathrm{~mL}$ of methanol (10: 1 molar ratio of methanol to oleic acid) were subjected to esterification reaction at different temperatures in the presence of the $0.1 \mathrm{~g}$ of Fe-H-ZSM-22. It seems that the reaction should be normally performed at temperatures close to the atmospheric boiling point of methanol. Due to the low efficiency of the esterification reaction at low temperatures, the investigation ought to be carried out at higher temperatures. The batch reactor was equipped with a reflux system that prevented methanol evaporation and loss. The reaction took place within
$48 \mathrm{~h}$ in order to ensure its completion. To identify the optimal temperature of esterification, the reaction between oleic acid and methanol was performed at different temperatures of $65^{\circ} \mathrm{C}$, $70^{\circ} \mathrm{C}, 80^{\circ} \mathrm{C}$, and $85^{\circ} \mathrm{C}$ (Table 5). The other reaction parameters were kept constant during the process. According to the experimental data, the maximum yield $\%$ of methyl oleate was achieved at $70^{\circ} \mathrm{C}$. A biodiesel yield $\%$ of about $16.78 \%$ was obtained at $65^{\circ} \mathrm{C}$ compared to $26.94 \%$ at $70^{\circ} \mathrm{C}$. The reason for this phenomenon is that the viscosity of the oil declined significantly with temperature increment, resulting in better mixing of oleic acid with methanol and easier mass diffusion. Also, glycerol precipitates more easily with temperature rise, causing a higher biodiesel production. In contrast, for temperatures above $70^{\circ} \mathrm{C}$, the biodiesel yield dropped considerably, ascribed to the fact that, at relatively high temperatures, side reactions such as hydrolysis of methyl esters may be intensified, leading to lower biodiesel production. Therefore, the saponification reaction was carried out by increasing the temperature above $70^{\circ} \mathrm{C}$.

3.4.2. Effect of $\mathrm{KOH}$ Concentration. Additional experiments were performed at $65^{\circ} \mathrm{C}, 20: 1$, and $30: 1$ of methanol to oleic acid molar ratios, with the amounts of $0.05,0.1$, and $0.2 \mathrm{~g}$ of $\mathrm{KOH}$ and in the presence of $0.3 \mathrm{~g}$ of Fe-H-ZSM-22. Figure 9 shows the conversion\% of oleic acid at two different levels of methanol to oleic acid ratio.

The yield $\%$ of methyl oleate production is also presented in Table 5. The results show that although increasing $\mathrm{KOH}$ increases the conversion percentage of oleic acid, it reduces the production yield $\%$ of methyl oleate considerably. The reaction of fatty acid with methanol in an alkaline environment produces soap (saponification process). A high $\mathrm{KOH}$ concentration prevents the formation of methyl oleate $[61,62]$. Thereby, the esterification experiments in this study were extended in the absence of $\mathrm{KOH}$.

3.4.3. Effect of Molar Ratio of Methanol to Oleic Acid. The effect of various molar ratios of methanol to oleic acid $(10: 1,20: 1$, and $30: 1)$ on the yield of produced methyl ester 


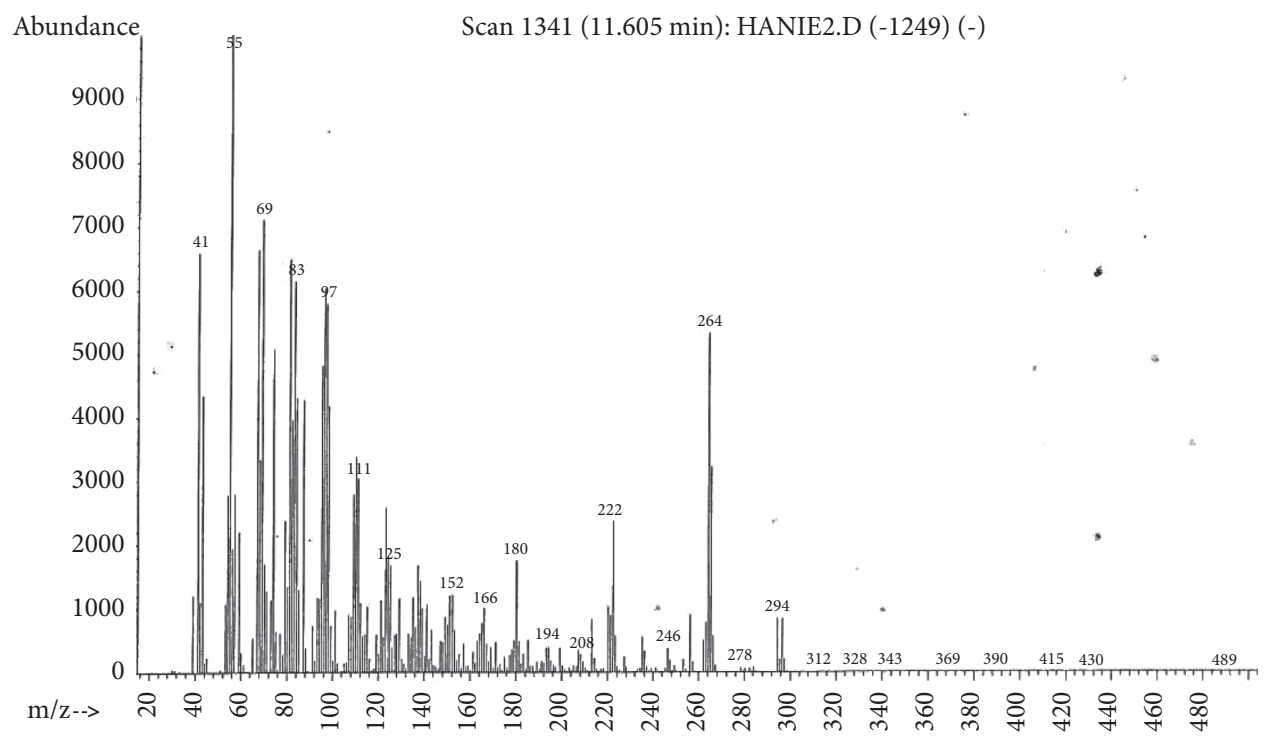

FiguRE 8: GC-MS chromatogram of methyl oleate.

TABLE 5: Yield\% of methyl oleate using Fe-H-ZSM-22.

\begin{tabular}{|c|c|c|c|c|c|c|}
\hline Entry & $\mathrm{T}\left({ }^{\circ} \mathrm{C}\right)$ & Methanol/oil molar ratio & Catalyst weight $(\mathrm{g})$ & Reaction time (h) & $\mathrm{KOH}(\mathrm{g})$ & Yield (\%) \\
\hline 1 & 65 & $10: 1$ & 0.1 & 48 & 0 & 16.78 \\
\hline 2 & 70 & $10: 1$ & 0.1 & 48 & 0 & 26.94 \\
\hline 3 & 80 & $10: 1$ & 0.1 & 48 & 0 & 8.61 \\
\hline 4 & 85 & $10: 1$ & 0.1 & 48 & 0 & 8.16 \\
\hline 5 & 65 & $20: 1$ & 0.3 & 48 & 0.05 & 24.11 \\
\hline 6 & 65 & $20: 1$ & 0.3 & 48 & 0.1 & 21.66 \\
\hline 7 & 65 & $20: 1$ & 0.3 & 48 & 0.2 & 8.38 \\
\hline 8 & 65 & $30: 1$ & 0.3 & 48 & 0.05 & 9.91 \\
\hline 9 & 65 & $30: 1$ & 0.3 & 48 & 0.1 & 9.43 \\
\hline 10 & 65 & $30: 1$ & 0.3 & 48 & 0.2 & 1.88 \\
\hline 11 & 65 & $10: 1$ & 0.1 & 48 & 0 & 26.17 \\
\hline 12 & 65 & $20: 1$ & 0.1 & 48 & 0 & 22.57 \\
\hline 13 & 65 & $30: 1$ & 0.1 & 48 & 0 & 10.47 \\
\hline 14 & 65 & $10: 1$ & 0.02 & 48 & 0 & 22.22 \\
\hline 15 & 65 & $10: 1$ & 0.08 & 48 & 0 & 25.22 \\
\hline 16 & 65 & $10: 1$ & 0.1 & 48 & 0 & 26.17 \\
\hline 17 & 65 & $10: 1$ & 0.2 & 48 & 0 & 26.94 \\
\hline 18 & 65 & $10: 1$ & 0.3 & 48 & 0 & 47 \\
\hline 19 & 70 & $10: 1$ & 0.3 & 4 & 0 & 5.7 \\
\hline 20 & 70 & $10: 1$ & 0.3 & 8 & 0 & 8.95 \\
\hline 21 & 70 & $10: 1$ & 0.3 & 16 & 0 & 21.42 \\
\hline 22 & 70 & $10: 1$ & 0.3 & 24 & 0 & 23.09 \\
\hline 23 & 70 & $10: 1$ & 0.3 & 48 & 0 & 47.17 \\
\hline
\end{tabular}

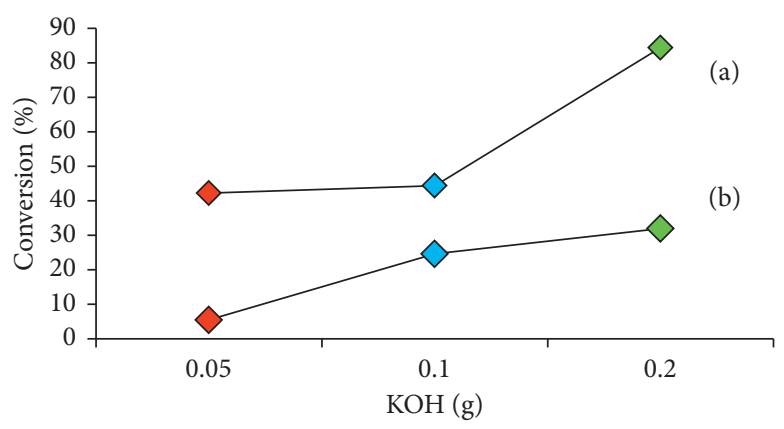

Figure 9: Conversion $\%$ of oleic acid in $65^{\circ} \mathrm{C}, 48 \mathrm{~h}$, and $0.1 \mathrm{~g}$ of Fe-H-ZSM-22 catalyst at (a) methanol to oleic acid molar ratio of $20: 1$ and (b) methanol to oleic acid molar ratio of $30: 1$. 
was investigated at $65^{\circ} \mathrm{C}$ for $48 \mathrm{~h}$ over $0.1 \mathrm{~g}$ of the $\mathrm{Fe}-\mathrm{H}-\mathrm{ZSM}$ 22 catalyst and different amounts of methanol. The yield $\%$ of methyl oleate reached $26.17 \%, 22.57$, and $10.47 \%$ at the molar ratios of $10: 1,20: 1$, and $30: 1$, respectively. The product yield decreased as the reactant molar ratio (alcohol to oil) increased because raising the concentration of methanol increases the dissolution of glycerin in biodiesel, which affects its purity considerably. Methanol is an emulsifier that helps form a stable emulsion. In the present study, the optimum molar ratio of oil to alcohol was found to be $1: 10$, which resulted in the highest yield of methyl oleate.

3.4.4. Effect of Catalyst Concentration. To identify the optimal catalyst concentration, five levels of catalyst were tested at $65^{\circ} \mathrm{C}$, a $10: 1$ methanol to oleic acid molar ratio, and different concentrations of Fe-H-ZSM-22 catalyst $(0.02 \mathrm{~g}$, $0.08 \mathrm{~g}, 0.1 \mathrm{~g}, 0.2 \mathrm{~g}$, and $0.3 \mathrm{~g}$ ) for $48 \mathrm{~h}$. The catalyst dosage (weight percent of catalyst in the feed) corresponded to $1 \mathrm{wt}$ $\%, 3 \mathrm{wt} \%, 5 \mathrm{wt} \%, 7 \mathrm{wt} \%$, and $11 \mathrm{wt} \%$, respectively. The yield percentages of the products were reported as $22.22 \%$, $25.22 \%, 26.17 \%, 26.94 \%$, and $47.17 \%$, corresponding to $1 \mathrm{wt}$ $\%$ to $11 \mathrm{wt} \%$, in the order mentioned above, respectively. Also, the conversion $\%$ of oleic acid increased from $15.5 \%$ to $23.8 \%$ by increasing the catalyst wt $\%$ from 1 to $11 \%$. In other words, the addition of a certain amount of catalyst improves the reaction rate, conversion\% of oleic acid, and product yield. Thus, due to the incredible cost increment, the optimum catalyst dosage was selected as $11 \mathrm{wt} \%(0.3 \mathrm{~g})$.

3.4.5. Effect of Reaction Time. The effect of different reaction times $(4,8,16,24$, and $48 \mathrm{~h})$ on the efficiency of the esterification of oleic acid was further examined. The experimental results were obtained at $65^{\circ} \mathrm{C}$ with $0.1 \mathrm{~g}$ of $\mathrm{Fe}-\mathrm{H}$ ZSM-22. By increasing the reaction time from $4 \mathrm{~h}$ to $24 \mathrm{~h}$, the yield increased from $5.4 \%$ to $23.09 \%$; however, prolonged reaction time might lead to an increase in energy consumption. The methyl oleate yield $\%$ reached its highest value $(47.17 \%)$ after $48 \mathrm{~h}$. Further increasing the reaction time had no significant impact on the yield percent, which was attributed to the achievement of an equilibrium state or the decomposition of the main product. Thereupon, increasing the time by more than $48 \mathrm{~h}$ is not cost effective. This rising trend was detected for all the catalysts, indicating that the optimum reaction time is $48 \mathrm{~h}$. Thereby, according to the results, the optimum reaction operating conditions were found to be as follows: reaction temperature of $70^{\circ} \mathrm{C}$, catalyst weight percent of $11 \%$, reaction time of $48 \mathrm{~h}$, and methanol to oleic acid ratio of $10: 1$, which resulted in the highest yield of methyl oleate. Regarding the experimental data, similar optimum conditions were determined with other catalysts of Sr-H-ZSM-22 and Zr-H-ZSM-22. The results of the optimization experiments over the Fe-H-ZSM-22 catalyst are reported in Table 5.

The esterification reactions were conducted in similar conditions three times, and the yield percentages of the oleic acid were calculated. Moreover, all tests were performed under steady-state conditions. No significant differences were observed between the experimental results, indicating that the results are reproducible. The esterification reaction generally is performed using acidic catalysts, while the reaction proceeds slowly. In this regard, numerous studies have been devoted to adjusting different parameters, including catalyst type, alcohol to oil ratio, temperature, time, and catalyst concentration, to improve reaction yield [63]. Different zeolites have been attracted much attention as efficient catalysts for esterification reactions. Among the various types of zeolites, many studies have been conducted on the use of ZSM-5 and ZSM-11 in biodiesel production $[63,64]$. The sizes of cavities of the ZSM-22 structure are smaller than those of ZSM-5 and ZSM-11, which leads to increasing the selectivity and the number of active acid sites [53]. The structural properties of ZSM-22 make it an efficient and cost-effective catalyst for biodiesel production. Since ZSM-22 zeolite has rarely been used as a catalyst in the esterification process, there are few studies on the catalytic performance of ZSM-22. Therefore, the catalytic activity of the ZSM-22-based catalyst (synthesized in this study) was compared with the results of the other catalysts used in the esterification of oleic acid with methanol [64]. According to reference [64], the yield percent of biodiesel is in the range of 55-100\%. 100\% maximum yield percent was reported in the case of $\mathrm{SO}_{4}^{2-} / \mathrm{La}_{2} \mathrm{O}_{3} / \mathrm{H}-\mathrm{ZSM}-5\left(100^{\circ} \mathrm{C}\right.$, methanol to oil $=45$ : 1 , and catalyst concentration of $10 \mathrm{wt} \%$ ), whereas $55 \%$ minimum yield percent was obtained for H-ZSM- 5 modified with citric acid. In the present study, the maximum yield $\%$ of methyl oleate using Fe-H-ZSM-22 was $47.17 \%$, which can be improved using other metals in the catalyst combination. Differences between the experimental results obtained and the reported results are due to the use of higher ratios of methanol to oil, higher temperature, homogeneous acid catalyst such as citric acid and sulfuric acid, and more metal concentration on the catalyst. The considerable properties of the ZSM-22-based catalyst (such as high selectivity) along with the core-shell structural characteristics (leading to increased reusability) have made it a proper candidate for esterification reaction.

3.4.6. The Effect of Metal Loading and $\mathrm{SiO}_{2}$ Coverage on the Catalytic Activity of ZSM-22-Based Catalysts. The catalytic activity of ZSM-22-based catalysts (loaded with different metals) was investigated for the esterification of oleic acid with methanol. The yield percent was obtained for each catalyst, and Table 6 presents a comparison with the results of the core-shell catalysts. The results show that the catalytic activities of these catalysts increased in the following order: Sr-H-ZSM-22 < Fe-H-ZSM-22 < Zr-H-ZSM-22. The same tendency was also observed in the core-shell structures, although the corresponding core-shell structures were generally less active than metal-loaded ZSM-22 (considering the yield $\%$ after $48 \mathrm{~h}$ ). This finding is probably due to the coverage of Lewis acid sites of the catalyst surface, causing the subsequent deactivation of the catalysts. It is worth noting, however, that the activity of catalysts is completely recovered by simple washing with ethanol. To conclude, the results demonstrate that the zirconium-containing $\mathrm{H}$-ZSM22 can efficiently catalyze the esterification of oleic acid with 
TABLE 6: The yield $\%$ of methyl oleate with different catalysts at $70^{\circ} \mathrm{C}$, catalyst weight percent $=11 \%$, and methanol to oleic acid molar ratio $=10: 1$.

\begin{tabular}{|c|c|c|c|c|c|}
\hline \multirow{2}{*}{ Catalyst } & \multicolumn{5}{|c|}{ Yield (\%) } \\
\hline & $4 \mathrm{~h}$ & $8 \mathrm{~h}$ & $16 \mathrm{~h}$ & $24 \mathrm{~h}$ & $48 \mathrm{~h}$ \\
\hline Zr-H-ZSM-22 & 5.51 & 15.06 & 21.54 & 29.04 & 48.07 \\
\hline Fe-H-ZSM-22 & 5.7 & 8.95 & 21.42 & 23.09 & 47.17 \\
\hline Sr-H-ZSM-22 & 5.18 & 8.02 & 18.15 & 21.54 & 29.55 \\
\hline Zr-H-ZSM-22@SiO & 21.72 & 22.34 & 24.51 & 26.11 & 44.24 \\
\hline Fe-H-ZSM-22@SiO & 15.78 & 17.19 & 21.13 & 24.64 & 35.88 \\
\hline Sr-H-ZSM-22@SiO & 6.43 & 13.74 & 19.08 & 20.14 & 35.56 \\
\hline
\end{tabular}

TABLE 7: Reusability study of catalysts used in esterification reaction at $70^{\circ} \mathrm{C}, 48 \mathrm{~h}$, catalyst weight percent $=11 \%$, and methanol to oleic acid molar ratio $=10: 1$.

\begin{tabular}{lccc}
\hline Catalyst & & Yield (\%) & \\
& $48 \mathrm{~h}$ (without reusability) & 48h (reusability first run) & 48 h (reusability second run) \\
\hline $\mathrm{Zr-H-ZSM-22}$ & 48.07 & 46.7 & 45.2 \\
Fe-H-ZSM-22 & 47.17 & 45.28 & 43 \\
Sr-H-ZSM-22 & 29.55 & 27 & 25.73 \\
Zr-H-ZSM-22@SiO & 44.24 & 43.68 & 41.89 \\
Fe-H-ZSM-22@SiO & 35.88 & 32.12 & 30.04 \\
Sr-H-ZSM-22@SiO & 35.56 & 33.15 & 31.8 \\
\hline
\end{tabular}

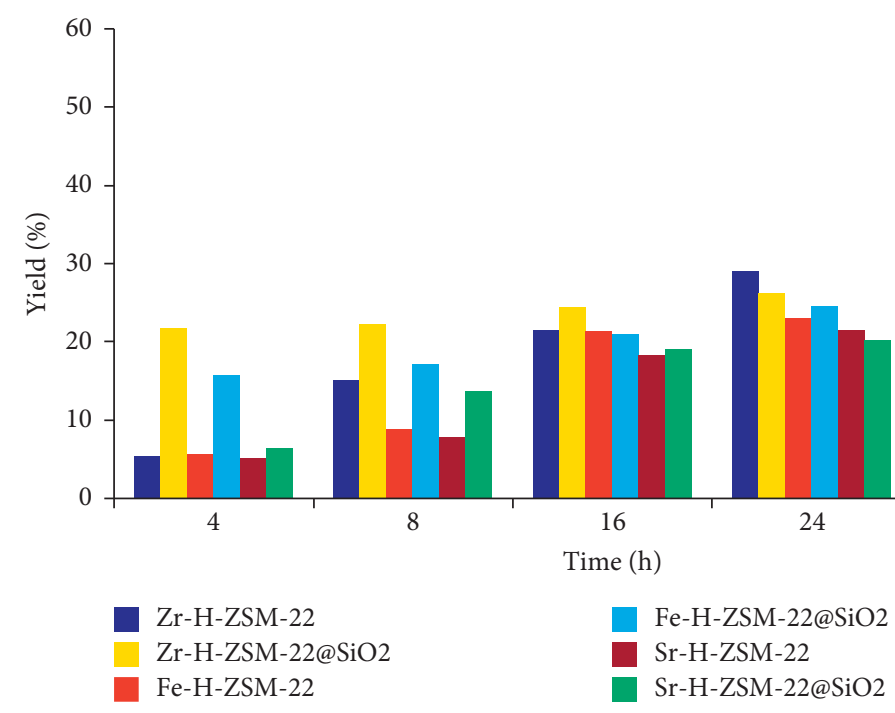

Figure 10: The yield\% of biodiesel production.

methanol due to being less active as $\mathrm{SiO}_{2}$ coverage increases. In all the tested reactions, $\mathrm{Zr}-\mathrm{H}-\mathrm{ZSM}-22$ and $\mathrm{Zr}-\mathrm{H}-\mathrm{ZSM}-$ $22 @ \mathrm{SiO}_{2}$ were found to be stable and reusable without significant loss of activity.

The results further show that the esterification reaction over H-ZSM-22 is considerably faster than with ZSM-22, probably due to the proton and the corresponding lower activation energy of the addition step. The experiments revealed that these reactions were catalyzed faster by homogeneous acid catalysts yielding over $90 \%$. This result is consistent with the findings of other researchers as well. $\mathrm{Hu}$ et al. used a variety of Zr-based catalysts and showed that the maximum yield\% for the esterification of triglyceride was achieved at $60 \mathrm{~min}$ and $200^{\circ} \mathrm{C}$ over $\mathrm{ZrO}_{2} / \mathrm{SBA}-15$ (out of various catalysts synthesized with zirconium), which was reported to be a superior catalytic activity [65]. They further reported that upgrading catalysts by sulfonic acid can enhance catalytic activity considerably. Sulfonic acid is an extremely strong acid that may cause reparable corrosive effects during combustion. To prevent corrosion problems in diesel engines, the use of mineral acids was not considered in the present research, and this study only investigated the effect of metal loading and structure modification with silica coverage. Certainly, under real conditions, using small amounts of homogeneous acids such as sulfuric acid is necessary. Using ZSM-22 catalyst, the yield\% of methyl oleate reached $16.06 \%$, and in the presence of H-ZSM-22, the yield increased to $26.11 \%$.

The catalyst concentration used in the esterification reaction must be controlled and adjusted in order to perform 
a green and cost-effective process. According to the strict environmental legislation, the reusability of catalysts is strongly recommended to reduce the environmental pollution. In this study, the catalyst was filtered and recovered after $48 \mathrm{~h}$, washed several times with double distilled water, and reused for 2 entries in an esterification reaction. The results show that all the presented catalysts in Table 7 preserve their catalytic performance after two runs with no significant reduction in catalytic activity. The $48.07 \%$ yield of the alkyl ester (methyl oleate) was dropped to $45.2 \%$ after the second recovery of the $\mathrm{Zr}-\mathrm{H}-\mathrm{ZSM}-22$ catalyst.

\section{Conclusion}

ZSM-22 has microporous canals, and its activity reduces due to the small pores. Also, modifying the zeolite surface causes the formation of mesoporous structures. This will increase the catalytic activity of zeolite. In order to illustrate the dependence of the metals and core-shell structures on the reaction rate, various tests were designed and carried out. The yield percent of methyl oleate (as biodiesel) upon the metal immobilized zeolites and their core-shell structures was measured at five reaction times $(4 \mathrm{~h}-48 \mathrm{~h})$. Figure 10 shows the yield\% of esterification of oleic acid with methanol over Zr-H-ZSM-22, Sr-H-ZSM-22, and Fe-H-ZSM-22. The efficiency of the catalysts is raised in the order of Sr-H-ZSM$22<\mathrm{Fe}-\mathrm{H}-\mathrm{ZSM}-22<\mathrm{Zr}-\mathrm{H}-\mathrm{ZSM}-22$. Also, it was found that the silica coverage of the catalysts decreased the catalytic efficiency due to the disability of some of the active Lewis sites.

\section{Data Availability}

Data are available upon request.

\section{Conflicts of Interest}

The authors declare that they have no conflicts of interest.

\section{Acknowledgments}

The authors thank the Alzahra Research Council for its financial support.

\section{References}

[1] V. Ş. Ediger, "An integrated review and analysis of multienergy transition from fossil fuels to renewables," Energy Procedia, vol. 156, pp. 2-6, 2019.

[2] D. Ansari and F. Holz, "Between stranded assets and green transformation: fossil-fuel-producing developing countries towards 2055," World Development, vol. 130, Article ID 104947, 2020.

[3] L. Branchini, P. Cagnoli, A. De Pascale, F. Lussu, V. Orlandini, and E. Valentini, "Environmental assessment of renewable fuel energy systems with cross-media effects approach," Energy Procedia, vol. 81, pp. 655-664, 2015.

[4] S. T. Keera, S. M. El Sabagh, and A. R. Taman, "Castor oil biodiesel production and optimization," Egyptian Journal of Petroleum, vol. 27, no. 4, pp. 979-984, 2018.
[5] R. S. Capaz, E. M. de Medeiros, D. G. Falco, J. E. A. Seabra, P. Osseweijer, and J. A. Posada, "Environmental trade-offs of renewable jet fuels in Brazil: beyond the carbon footprint," The Science of the Total Environment, vol. 714, Article ID 136696, 2020.

[6] J. Suebsiri and M. Wilson, "A model of carbon capture and storage with demonstration of global warming potential and fossil fuel resource use efficiency," Energy Procedia, vol. 4, pp. 2465-2469, 2011.

[7] F. Martins, C. Felgueiras, and M. Smitková, "Fossil fuel energy consumption in European countries," Energy Procedia, vol. 153, pp. 107-111, 2018.

[8] G. S. Ha, M. M El-Dalatony, D. H Kim et al., "Biocomponentbased microalgal transformations into biofuels during the pretreatment and fermentation process," Bioresource Technology, vol. 302, Article ID 122809, 2020.

[9] O. S. Stamenković, K. Siliveru, V. B. Veljković et al., "Production of biofuels from sorghum," Renewable and Sustainable Energy Reviews, vol. 124, Article ID 109769, 2020.

[10] P. S. Nigam and A. Singh, "Production of liquid biofuels from renewable resources," Progress in Energy and Combustion Science, vol. 37, no. 1, pp. 52-68, 2011.

[11] E. S. Shuba and D. Kifle, "Microalgae to biofuels: 'Promising' alternative and renewable energy, review," Renewable and Sustainable Energy Reviews, vol. 81, pp. 743-755, 2018.

[12] S. A. Sadeek, E. A. Mohammed, M. Shaban, M. T. H. Abou Kana, and N. A. Negm, "Synthesis, characterization and catalytic performances of activated carbon-doped transition metals during biofuel production from waste cooking oils," Journal of Molecular Liquids, vol. 306, Article ID 112749, 2020.

[13] B. G. Subhadra, "Sustainability of algal biofuel production using integrated renewable energy park (IREP) and algal biorefinery approach," Energy Policy, vol. 38, no. 10, pp. 5892-5901, 2010.

[14] D. Singh, D. Sharma, S. L. Soni, S. Sharma, P. Kumar Sharma, and A. Jhalani, "A review on feedstocks, production processes, and yield for different generations of biodiesel," Fuel, vol. 262, Article ID 116553, 2020.

[15] J. Ching-Velasquez, R. Fernández-Lafuente, R. C. Rodrigues et al., "Production and characterization of biodiesel from oil of fish waste by enzymatic catalysis," Renewable Energy, vol. 153, pp. 1346-1354, 2020.

[16] G. Y. Yew, S. Y. Lee, P. Loke Show et al., "Recent advances in algae biodiesel production: from upstream cultivation to downstream processing," Bioresource Technology Reports, vol. 7, Article ID 100227, 2019.

[17] G. H. Soegiantoro, J. Chang, P. Rahmawati, M. F. Christiani, and Z. Mufrodi, "Home-made eco green biodiesel from chicken fat (CIAT) and waste cooking oil (PAIL)," Energy Procedia, vol. 158, pp. 1105-1109, 2019.

[18] S. M. Safieddin Ardebili and A. Khademalrasoul, "An analysis of liquid-biofuel production potential from agricultural residues and animal fat (case study: khuzestan Province)," Journal of Cleaner Production, vol. 204, pp. 819-831, 2018.

[19] A. Nikkhah, M. El Haj Assad, K. A. Rosentrater, S. Ghnimi, and S. Van Haute, "Comparative review of three approaches to biofuel production from energy crops as feedstock in a developing country," Bioresource Technology Reports, vol. 10, Article ID 100412, 2020.

[20] C.-L. Chiang, K.-S. Lin, C.-W. Shu, J. C.-S. Wu, K. C.-W. Wu, and Y.-T. Huang, "Enhancement of biodiesel production via sequential esterification/transesterification over solid 
superacidic and superbasic catalysts," Catalysis Today, vol. 348, 2019.

[21] S. H. Shuit and S. H. Tan, "Esterification of palm fatty acid distillate with methanol via single-step pervaporation membrane reactor: a novel biodiesel production method," Energy Conversion and Management, vol. 201, Article ID 112110, 2019.

[22] S. X. Tan, S. Lim, H. C. Ong, and Y. L. Pang, "State of the art review on development of ultrasound-assisted catalytic transesterification process for biodiesel production," Fuel, vol. 235, pp. 886-907, 2019.

[23] G. O. Ferrero, E. M. Sánchez Faba, A. A. Rickert, and G. A. Eimer, "Alternatives to rethink tomorrow: biodiesel production from residual and non-edible oils using biocatalyst technology," Renewable Energy, vol. 150, pp. 128-135, 2020.

[24] B. Karmakar and G. Halder, "Progress and future of biodiesel synthesis: advancements in oil extraction and conversion technologies," Energy Conversion and Management, vol. 182, pp. 307-339, 2019.

[25] C. M. Fernández, M. J. Ramos, A. Pérez, and J. F. Rodríguez, "Production of biodiesel from winery waste: extraction, refining and transesterification of grape seed oil," Bioresource Technology, vol. 101, no. 18, pp. 7030-7035, 2010.

[26] D. N. Thoai, I. Chanakaewsomboon, K. Prasertsit, S. Photaworn, and C. Tongurai, "A novel inspection of mechanisms in conversion of refined palm oil to biodiesel with alkaline catalyst," Fuel, vol. 256, Article ID 115831, 2019.

[27] K. Malins, "The potential of K3PO4, K2CO3, Na3PO4 and $\mathrm{Na} 2 \mathrm{CO} 3$ as reusable alkaline catalysts for practical application in biodiesel production," Fuel Processing Technology, vol. 179, pp. 302-312, 2018.

[28] A. S. Silitonga, H. H. Masjuki, T. M. I. Mahlia, H. C. Ong, A. E. Atabani, and W. T. Chong, "A global comparative review of biodiesel production from jatropha curcas using different homogeneous acid and alkaline catalysts: study of physical and chemical properties," Renewable and Sustainable Energy Reviews, vol. 24, pp. 514-533, 2013.

[29] A. Šalić, A. Jurinjak Tušek, M. Gojun, and B. Zelić, "Biodiesel purification in microextractors: choline chloride based deep eutectic solvents vs. water," Separation and Purification Technology, vol. 242, Article ID 116783, 2020.

[30] Z. Ç. Okumuş, T. H. Doğan, and H. Temur, "Removal of water by using cationic resin during biodiesel purification," Renewable Energy, vol. 143, pp. 47-51, 2019.

[31] R. M. Mohamed, G. A. Kadry, H. A. Abdel-Samad, and M. E. Awad, "High operative heterogeneous catalyst in biodiesel production from waste cooking oil," Egyptian Journal of Petroleum, vol. 29, no. 1, pp. 59-65, 2020.

[32] M. Masteri-Farahani, M.-S. Hosseini, and N. Forouzeshfar, "Propyl-SO3H functionalized graphene oxide as multipurpose solid acid catalyst for biodiesel synthesis and acid-catalyzed esterification and acetalization reactions," Renewable Energy, vol. 151, pp. 1092-1101, 2020.

[33] J. C. Lee, B. Lee, Y. S. Ok, and H. Lim, "Preliminary technoeconomic analysis of biodiesel production over solid-biochar," Bioresource Technology, vol. 306, Article ID 123086, 2020.

[34] A. Vávra, M. Hájek, and F. Skopal, "Acceleration and simplification of separation by addition of inorganic acid in biodiesel production," Journal of Cleaner Production, vol. 192, pp. 390-395, 2018.

[35] F. Kesserwan, M. N. Ahmad, M. Khalil, and H. El-Rassy, "Hybrid $\mathrm{CaO} / \mathrm{Al} 2 \mathrm{O} 3$ aerogel as heterogeneous catalyst for biodiesel production," Chemical Engineering Journal, vol. 385, Article ID 123834, 2020.

[36] B. Nath, B. Das, P. Kalita, and S. Basumatary, "Waste to value addition: utilization of waste Brassica nigra plant derived novel green heterogeneous base catalyst for effective synthesis of biodiesel," Journal of Cleaner Production, vol. 239, Article ID 118112, 2019.

[37] M. Shaban, R. Hosny, A. M. Rabie et al., "Zinc aluminate nanoparticles: preparation, characterization and application as efficient and economic catalyst in transformation of waste cooking oil into biodiesel," Journal of Molecular Liquids, vol. 302, Article ID 112377, 2020.

[38] R. V. Quah, Y. H. Tan, N. M. Mubarak, M. Khalid, E. C. Abdullah, and C. Nolasco-Hipolito, "An overview of biodiesel production using recyclable biomass and non-biomass derived magnetic catalysts," Journal of Environmental Chemical Engineering, vol. 7, no. 4, Article ID 103219, 2019.

[39] B. J. B. Silva, L. V. de Sousa, P. H. L. Quintela et al., "Preparation of ZSM-22 zeolite with hierarchical pore structure," Materials Letters, vol. 218, pp. 119-122, 2018.

[40] R. Feng, X. Yan, X. Hu, J. Wu, and Z. Yan, "Direct synthesis of b-axis oriented H-form ZSM-5 zeolites with an enhanced performance in the methanol to propylene reaction," $M i$ croporous and Mesoporous Materials, vol. 302, Article ID 110246, 2020.

[41] W. Xie and H. Wang, "Synthesis of heterogenized polyoxometalate-based ionic liquids with Brönsted-Lewis acid sites: a magnetically recyclable catalyst for biodiesel production from low-quality oils," Journal of Industrial and Engineering Chemistry, vol. 87, 2020.

[42] H. Widayat, H. Hadiyanto, and H. Satriadi, W. I. S. T. Astuti, B. Cahyono, W. I. S. T. Astuti, and P. Febrianti, Synthesis of zeolite X molecular sieve from geothermal solid waste," Materials Today: Proceedings, vol. 13, pp. 137-142, 2019.

[43] G. Yang, J. He, Y. Yoneyama, and N. Tsubaki, "H-ZSM-5/ cobalt/silica capsule catalysts with different crystallization time for direct synthesis of isoparaffins: simultaneous realization of space confinement effect and shape selectivity effect," in Natural Gas Conversion VIII, F. Bellot Noronha, M. Schmal, and C. Falabella Sousa-Aguiar, Eds., pp. 73-78, Elsevier, Amsterdam, Netherlands, 2007.

[44] Y. Fu, J. Jiang, Z. Chen, S. Ying, J. Wang, and J. Hu, "Rapid and selective removal of $\mathrm{Hg}(\mathrm{II})$ ions and high catalytic performance of the spent adsorbent based on functionalized mesoporous silica/poly(m-aminothiophenol) nanocomposite," Journal of Molecular Liquids, vol. 286, Article ID 110746, 2019.

[45] Ö. D. Bozkurt, N. Bağlar, S. Çelebi, and A. Uzun, "Screening of solid acid catalysts for etherification of glycerol with isobutene under identical conditions," Catalysis Today, vol. 357, 2019.

[46] E. Costa, J. Aguado, G. Ovejero, and P. Cañizares, "Conversion of guayule resin to $\mathrm{C} 1-\mathrm{C} 10$ hydrocarbons on zeolite based catalysts," Fuel, vol. 71, no. 1, pp. 109-113, 1992.

[47] G. T. Kokotailo, J. L. Schlenker, F. G. Dwyer, and E. W. Valyocsik, "The framework topology of ZSM-22: a high silica zeolite," Zeolites, vol. 5, no. 6, pp. 349-351, 1985.

[48] X. Wang, X. Zhang, and Q. Wang, "N-dodecane hydroisomerization over Pt/ZSM-22: controllable microporous Brönsted acidity distribution and shape-selectivity," Applied Catalysis A: General, vol. 590, Article ID 117335, 2020.

[49] M. S. Holm, S. Svelle, F. Joensen et al., "Assessing the acid properties of desilicated ZSM-5 by FTIR using CO and 2,4,6- 
trimethylpyridine (collidine) as molecular probes," Applied Catalysis A: General, vol. 356, no. 1, pp. 23-30, 2009.

[50] H. Singh Pali, A. Sharma, Y. Singh, and N. Kumar, "Sal biodiesel production using Indian abundant forest feedstock," Fuel, vol. 273, Article ID 117781, 2020.

[51] V. J. Inglezakis, "The concept of "capacity" in zeolite ionexchange systems," Journal of Colloid and Interface Science, vol. 281, no. 1, pp. 68-79, 2005.

[52] F. Goodarzi, I. P. Herrero, G. N. Kalantzopoulos et al., "Synthesis of mesoporous ZSM-5 zeolite encapsulated in an ultrathin protective shell of silicalite-1 for MTH conversion," Microporous and Mesoporous Materials, vol. 292, Article ID 109730, 2020

[53] A. K. Jamil, O. Muraza, and A. M. Al-Amer, "Microwaveassisted solvothermal synthesis of ZSM-22 zeolite with controllable crystal lengths," Particuology, vol. 24, pp. 138-141, 2016.

[54] G. Perego, M. Cesari, and G. Allegra, "Ordered and disordered structures in borosilicates with a pentasil-type framework," Journal of Applied Crystallography, vol. 17, no. 6, pp. 403-410, 1984.

[55] G. T. Kokotailo, S. L. Lawton, D. H. Olson, and W. M. Meier, "Structure of synthetic zeolite ZSM-5," Nature, vol. 272, no. 5652, pp. 437-438, 1978.

[56] G. T. Kokotailo, P. Chu, S. L. Lawton, and W. M. Meier, "Synthesis and structure of synthetic zeolite ZSM-11," Nature, vol. 275, no. 5676, pp. 119-120, 1978.

[57] P. del Campo, P. Beato, F. Rey et al., "Influence of postsynthetic modifications on the composition, acidity and textural properties of ZSM-22 zeolite," Catalysis Today, vol. 299, pp. 120-134, 2018.

[58] M. Dyballa, P. Becker, D. Trefz et al., "Parameters influencing the selectivity to propene in the MTO conversion on 10-ring zeolites: directly synthesized zeolites ZSM-5, ZSM-11, and ZSM-22," Applied Catalysis A: General, vol. 510, pp. 233-243, 2016.

[59] J. Luo, K. Kamasamudram, N. Currier, and A. Yezerets, "NH3-TPD methodology for quantifying hydrothermal aging of Cu/SSZ-13 SCR catalysts," Chemical Engineering Science, vol. 190, pp. 60-67, 2018.

[60] N. Katada, T. Tsubaki, and M. Niwa, "Measurements of number and strength distribution of Brønsted and Lewis acid sites on sulfated zirconia by ammonia IRMS-TPD method," Applied Catalysis A: General, vol. 340, no. 1, pp. 76-86, 2008.

[61] Y. Wang, S. O. Pengzhan Liu, and Z. Zhang, "Preparation of biodiesel from waste cooking oil via two-step catalyzed process," Energy Conversion and Management, vol. 48, no. 1, pp. 184-188, 2007.

[62] J. M. Encinar, J. F. González, and A. Rodríguez-Reinares, "Biodiesel from used frying oil. Variables affecting the yields and characteristics of the biodiesel," Industrial \& Engineering Chemistry Research, vol. 44, no. 15, pp. 5491-5499, 2005.

[63] P.-L. Boey, G. P. Maniam, and S. A. Hamid, "Performance of calcium oxide as a heterogeneous catalyst in biodiesel production: a review," Chemical Engineering Journal, vol. 168, no. 1, pp. 15-22, 2011.

[64] N. Fattahi, K. Triantafyllidis, R. Luque, and A. Ramazani, "Zeolite-based catalysts: a valuable approach toward ester bond formation," Catalysts, vol. 9, no. 9, pp. 758-781, 2019.

[65] N. Hu, Z. Kong, L. He et al., "Effective transesterification of triglyceride with sulphonated modified SBA-15 (SBA-15$\mathrm{SO} 3 \mathrm{H})$ : screening, process and mechanism," Inorganica Chimica Acta, vol. 482, pp. 846-853, 2018. 